\title{
Limitation of Acoustic Emission for identifying seeded defects in gearboxes
}

\author{
Chee Keong Tan, David Mba \\ School of Engineering, Cranfield University, Bedfordshire. MK43 0AL, UK \\ Tel: +44 (0) 1234-750 111 ext 2371, Fax: +44 (0) 1234-752376. \\ E-mail : c.k.tan@cranfield.ac.uk \& d.mba@cranfield.ac.uk
}

\begin{abstract}
Acoustic Emissions (AE) is gaining ground as a Non-Destructive Technique (NDT) for health diagnosis on rotating machinery. Vast opportunities exist for development of the AE technique on various forms of rotating machinery, including gearboxes. This paper reviews recent developments in application of $\mathrm{AE}$ to gear defect diagnosis. Furthermore, experimental results are presented that examine and explore the effectiveness of $\mathrm{AE}$ for gear defect diagnosis. It is concluded that application of $\mathrm{AE}$ to artificially seeded gear defect detection is fraught with difficulties, particularly for fault identification. In addition, the viability of the AE technique for gear defect detection by making observations from non-rotating components of a machine is called into question. Nevertheless, guidance is offered on applying the technique for monitoring the natural wear of gears.
\end{abstract}

Keywords: Acoustic Emission, condition monitoring, gear fault diagnosis, gear defect identification 


\section{Introduction}

Application of the high frequency Acoustic Emission (AE) technique in condition monitoring of rotating machinery has been growing over recent years. This is particularly true for bearing defect diagnosis and seal rubbing [1-5]. The main drawback with the application of the $\mathrm{AE}$ technique is the attenuation of the signal and as such the $\mathrm{AE}$ sensor has to be close to its source. However, it is often practical to place the AE sensor on the non-rotating member of the machine, such as the bearing or gear casing. Therefore, the AE signal originating from the defective component will suffer severe attenuation before reaching the sensor. Typical frequencies associated with AE activity range from $20 \mathrm{kHz}$ to $1 \mathrm{MHz}$.

Whilst vibration analysis on gear fault diagnosis is well established, the application of AE to this field is still in its infancy. In addition, there are limited publications on application of AE to gear fault diagnosis. Siores et al [6] explored several AE analysis techniques in an attempt to correlate all possible failure modes of a gearbox during its useful life. Failures such as excessive backlash, shaft misalignment, tooth breakage, scuffing and a worn tooth were seeded during tests. Siores correlated the various seeded failure modes of the gearbox with the AE amplitude, r.m.s. standard deviation and duration. It was concluded that the $\mathrm{AE}$ results could be correlated to various defect conditions. Sentoku [7] correlated tooth surface damage such as pitting to AE activity. An AE sensor was mounted on the gear wheel and the AE signature was transmitted from the sensor to data acquisition card across a mercury slip ring. It was concluded that AE amplitude and energy increased with increased pitting. 
Singh et al [8] assessed the transmissibility of AE's within a gearbox. The tests were performed with different torque levels using lead pencil breaks to simulate AE activity in the gearbox. This technique is known as the Nielsen source test. Various AE transmission paths were examined. One AE sensor was placed on the gear wheel to measure the initial strength of the signature and second sensor was mounted on the bearing pedestal to capture the transmitted signal. It was observed that greater attenuation was experienced for lighter loads though attenuation remained rather constant at the high load conditions. Singh et al concluded that the attenuation across the gearbox was an accumulation of losses across each individual interfaces within the transmission path and the optimum path of propagation will be the one with the smallest cumulative loss.

In a separate study, Singh et al [9] studied the feasibility of AE for gear fault diagnosis. In one test a simulated pit was introduced on the pitch line of a gear tooth using an Electrical Discharge Machining (EDM) process. An AE sensor and an accelerometer for comparative purposes were employed in both test cases. It was important to note that both the accelerometer and $\mathrm{AE}$ sensor were placed on the gearbox casing. It was observed that the AE amplitude increased with increased rotational speed and increased $\mathrm{AE}$ activity was observed with increased pitting. In a second test, periodically occurring peaks were observed when natural pitting started to appear after half an hour of operation. These AE activities increased as the pitting spread over more teeth. Singh et al concluded that $\mathrm{AE}$ could provide earlier detection over vibration monitoring for pitting of gears, but noted it could not be applicable at extremely high speeds or for unloaded gear conditions. 
Tandon et al. [10] performed an experiment to correlate AE parameters, such as peak amplitude, ringdown count and energy with gear defect size. Simulated pits on the pitch-line with constant depth $(500 \mu \mathrm{m})$ and varying diameters from 250 to $2200 \mu \mathrm{m}$ were introduced using spark erosion technique. Tandon et al observed that the monitored AE parameters increased with defect size (pit diameter) and load. Tandon et al also concluded that $\mathrm{AE}$ has a better detection capability over vibration since it was able to detect smaller pit sizes.

Al-Balushi et al [11] explored and compared the energy-based methods to the statistical methods (such as Kurtosis, Crest Factor etc) for diagnosis of a gear defect. Using the energy indexes, Al-Balushi et al was able to relate the square root of energy index, cumulative energy index and cumulative square root of energy index to broken tooth and pitting conditions. The energy-based method was further applied on the vibration data collected from a helicopter intermediate gearbox. Al-Balushi suggested that the proposed technique was applicable and effective in detection of incipient fault on helicopter gearboxes.

Toutountzakis et al [12] presented some interesting observations during the gear defect diagnosis testing. The test was performed on a back-to-back gearbox with a spur gear set of 49 and 65 teeth, using a variable speed controller to alter the rotational speed of the motor. The AE sensor used was placed on the pinion and a silver contact air-cooled slip ring was employed to transmit the AE signal for further processing. During the test, the rotational speed was varied from $600 \mathrm{rpm}$ to $1800 \mathrm{rpm}$, and observations of $\mathrm{AE}$ 
activity due to misalignment and natural pitting were observed. Toutountzakis et al concluded that $\mathrm{AE}$ technique demonstrated the potential for gear fault diagnosis.

Although the development of AE in gear diagnosis is in its infancy, the papers reviewed have illustrated the potential and viability of AE becoming a useful diagnostic tool in condition monitoring of gears. However, more detailed investigations are required to ensure this technique is robust and applicable for operational gearboxes. The purpose of this investigation was to validate the $\mathrm{AE}$ technique and determine an effective $\mathrm{AE}$ indicator for gear defect detection.

\section{Experimental set-up}

The test-rig employed for this investigation consisted of two identical oil-bath lubricated gearboxes, connected in a back-to-back arrangement, see figure 1 . The gear set employed were made of $045 \mathrm{M} 15$ steel without any heat treatment. The gears ( 49 and 65 teeth) had a module of $3 \mathrm{~mm}$, a pressure angle of $20^{\circ}$, and a surface roughness of between 2-3 $\mu \mathrm{m}$. Each gearbox had four identical ball bearings. A simple mechanism that permitted a pair of coupling flanges to be rotated relative to each other, and locked in position, was employed to apply torque to the gears. The effect of this process was to twist the shafts and lock in the torque within the loop of the back-to-back gearbox. Three torque values were used for the experiment: $0 \mathrm{Nm}, 55 \mathrm{Nm}$ and $110 \mathrm{Nm}$. The contact ratio of the gear was 1.77 . The motors used to drive the gearbox were single speed motors $(1.1 \mathrm{KW}$ and $0.55 \mathrm{KW})$ with a running speed of 745 and $1460 \mathrm{rpm}$ respectively. The lubricant employed was an EP SAE 80W-90, GL-4 API multi-grade 
gearbox oil, so as to keep natural pitting and wear to a minimum level during the seeded fault tests.

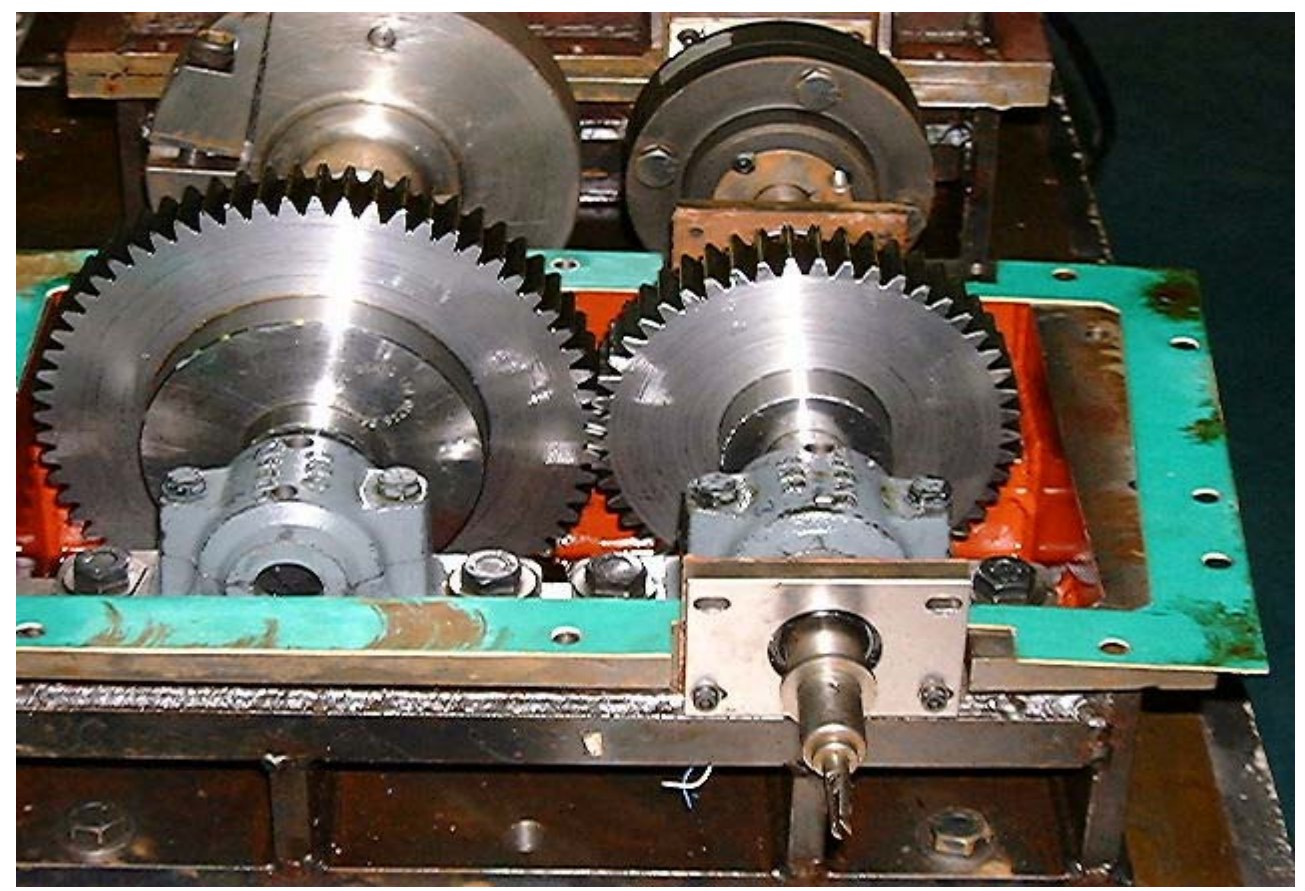

Figure 1 Test-rig gearboxes in back-to-back arrangement

\section{Sensors and Acquisition Systems}

The AE sensors used for this experiment were broadband type sensors with a relative flat response in the region between $100 \mathrm{KHz}$ to $1 \mathrm{MHz}$ (Model: WD, 'Physical Acoustics Corporation'). One sensor was placed on pinion (49 teeth) and the other on the bearing casing (figure 2) of the pinion shaft. The cable connecting the sensor placed on the pinion with the pre-amplifier was fed into the shaft and connected to a slip ring, see figure 3. This arrangement allowed the AE sensor to be placed as close as possible to the gear teeth. Both sensors were held in place with mechanical fixtures. A PH-12 slip rig manufactured by 'IDM Electronics Ltd' was employed. The slip ring used silver 
contacts and could accommodate up to 12 channels. The slip ring had an air intake where pressurised air was fed for cooling purposes at a rate of $1.4 \mathrm{~kg} / \mathrm{cm}^{2}$ (figure 3 ). The output signal from the AE sensors was pre-amplified at either 40 or $20 \mathrm{~dB}$. The signal output from the pre-amplifier was connected (i.e. via $\mathrm{BNC} /$ coaxial cable) directly to a commercial data acquisition card where a sampling rate of $10 \mathrm{MHz}$ was used during the tests. Prior to the analogue-to-digital converter (ADC), the card employed anti-aliasing filters that can be controlled directly in software.

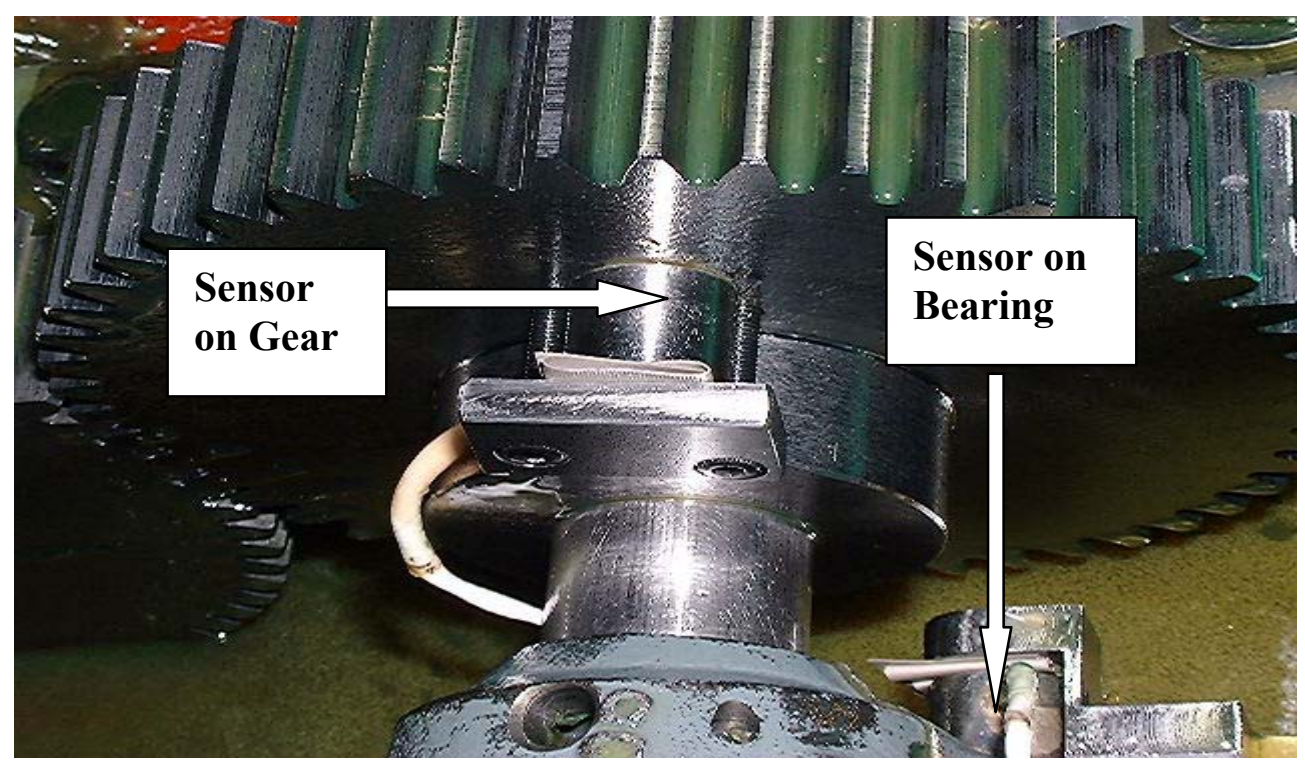

Figure 2 AE sensors located on the pinion and bearing casing. 


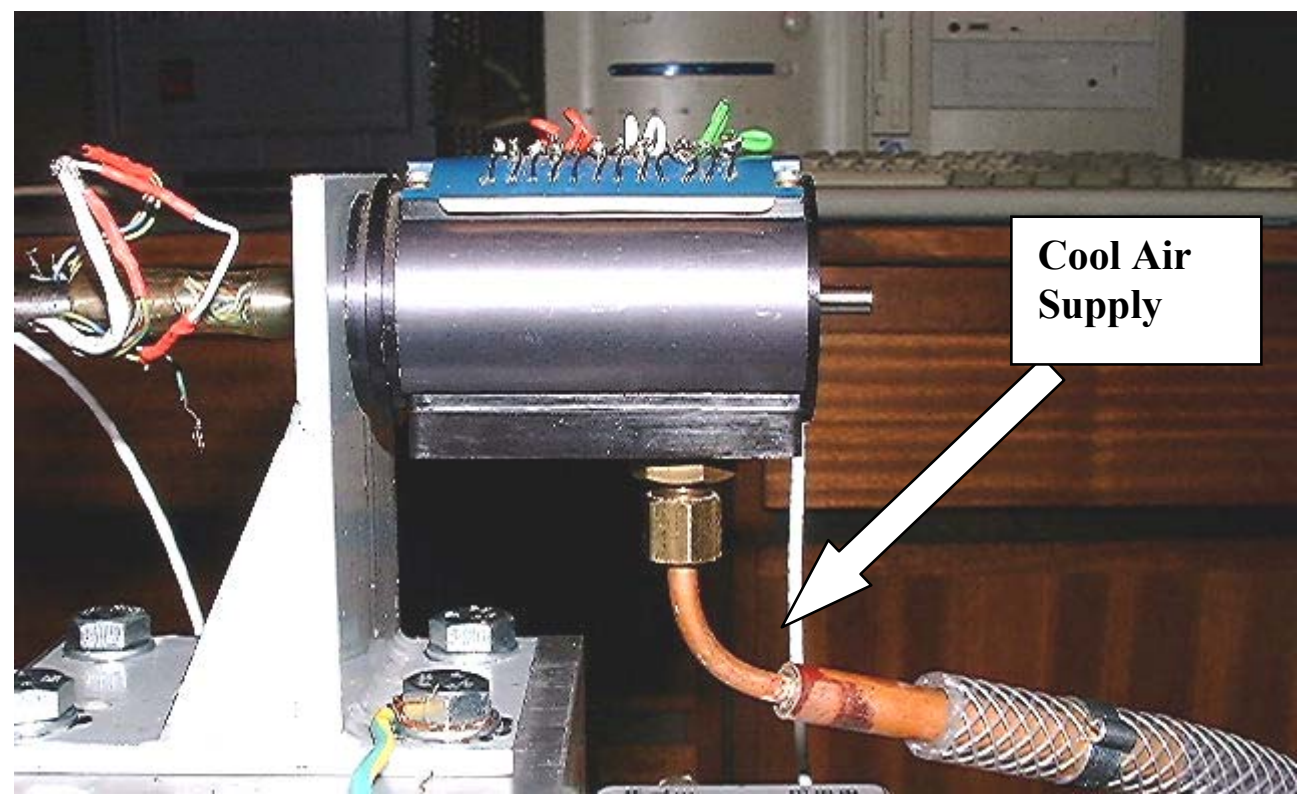

Figure $3 \quad$ Slip ring coupled with cool compressed air supply.

\section{Test Procedures}

The gearbox was run-in for more than 15 hours before the actual experiment was carried out. Prior to the start of the test, attenuation test on the gearbox components was undertaken in order to understand the characteristics of the test-rig.

The test started at a rotational speed of $745 \mathrm{rpm}$ with a seeded large addendum defect (extended from the pitch-line) measuring $12 \mathrm{~mm}$ along the face width by $3 \mathrm{~mm}$ from pitch-line to tooth tip (see figure 4). The seeded defect was introduced on the tooth flank of the pinion wheel using an engraving machine. The gearbox was run for 30 minutes prior to acquiring AE data for the no load condition. The gearbox was then shut down to adjust to the next torque level $(55 \mathrm{Nm})$. After another 30 minutes of continuous running, the AE data for this load condition was acquired. This procedure was repeated for the 
load condition of $110 \mathrm{Nm}$. These procedures were repeated at a higher rotational speed of $1460 \mathrm{rpm}$.

Based on the sampling rate of $10 \mathrm{MHz}$, the acquisition time available for recording was 0.0256 seconds which represented 0.32 (16 teeth) and 0.62 (30 teeth) revolutions of the pinion at 745 and $1460 \mathrm{rpm}$ respectively. By employing a trigger mechanism, only $\mathrm{AE}$ data from the portion of the pinion gear wheel where the defect was located was acquired. The trigger system was set such that the defective gear tooth was at the mid point of the acquisition window (0.0256 seconds), see figure 5 .

The AE parameters chosen for the gear defect diagnosis were; root mean square (r.m.s), energy and crest factor. The r.m.s. and energy are the most common AE parameters usually employed for diagnosis; whereas the crest factor was employed to measure the 'spikiness' of the AE signal which was expected to vary for these tests.

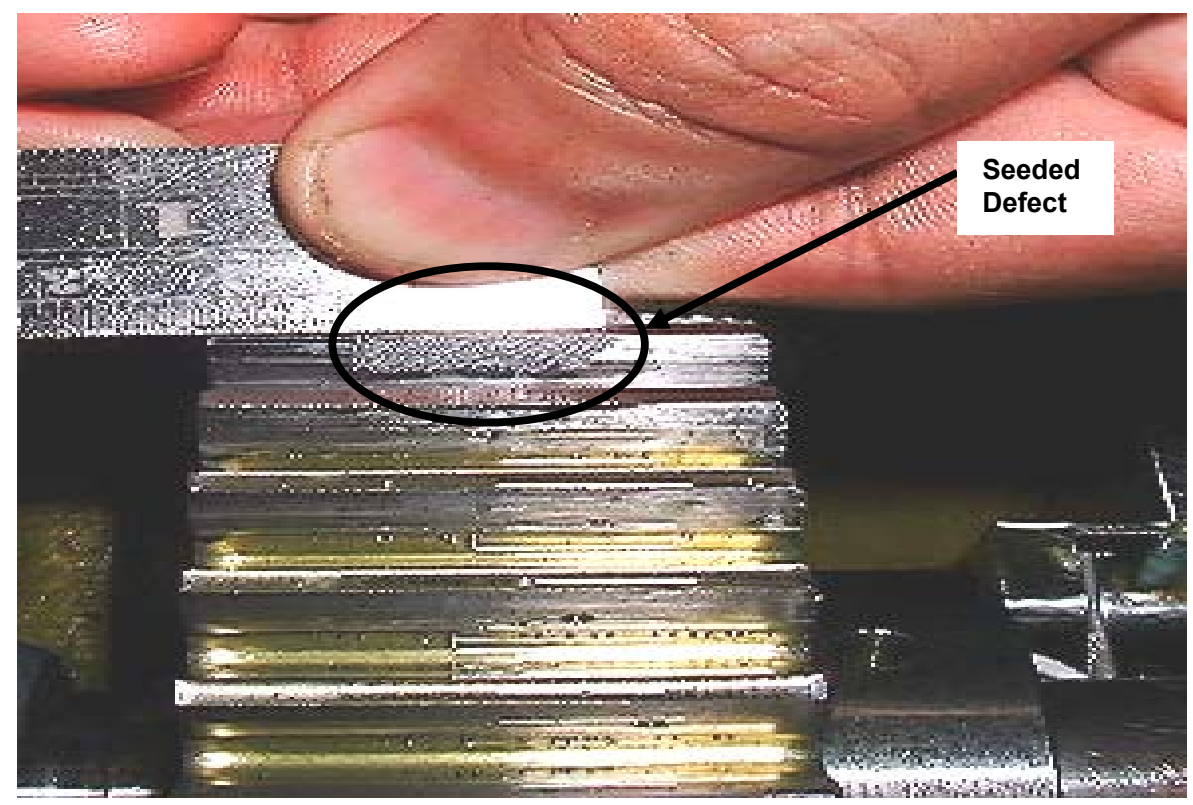

Figure 4 Seeded large addendum defect. 


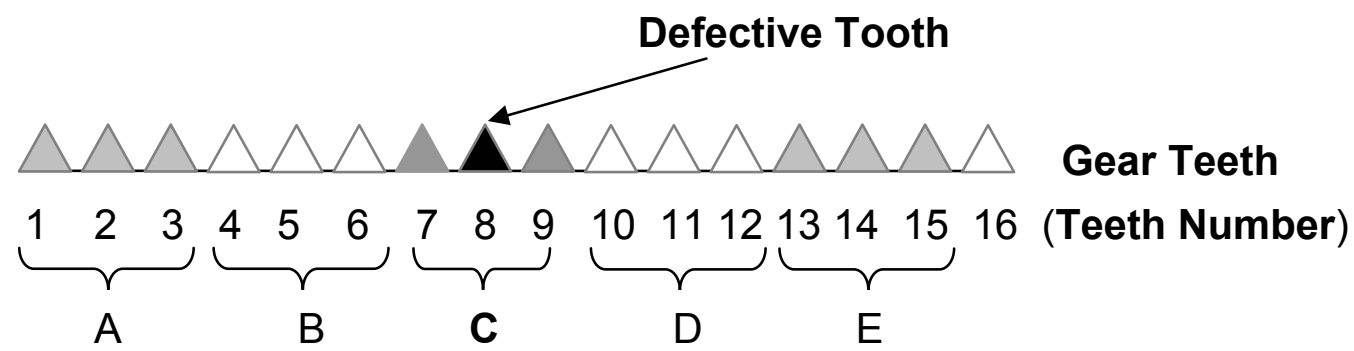

Figure 5 Sectioning of gear teeth for analysis.

\section{Attenuation Test}

A $0.5 \mathrm{~mm}$ diameter and $3 \mathrm{~mm}$ length $2 \mathrm{H}$ lead pencil was broken at different positions in order to establish the attenuation of the AE signal. This technique is known as the Nielsen source test. Figure 6 presents the schematic diagram for the attenuation test displaying the different simulation positions and different interfaces the AE signatures would have to propagate across. Table 1 shows the relative attenuation values. The reference signal employed for the attenuation calculations was the AE response from a lead break next to the AE sensor on the pinion gear. Five pencil breaks were acquired from each position and averaged.

The greatest attenuation of simulated AE signatures was observed on the bearing. This was expected due to the number of interfaces the AE signature would need to propagate across. The position of the balls in the bearing can affect the transmissibility of the AE signal. If a ball is in the loaded zone while the AE waves were travelling through, better transmissibility can be expected. Relatively high attenuation was also observed for lead 
breaks on the wheel (big gear). This was expected as the wheel is furthest away from the sensor; however, the attenuation values of lead breaks on the pinion and shaft were similar. It was expected that the attenuation would be greater on the shaft due to the interface between the shaft and the pinion gear but this was not the case. This is attributed to experimental errors and the close proximity at both locations.

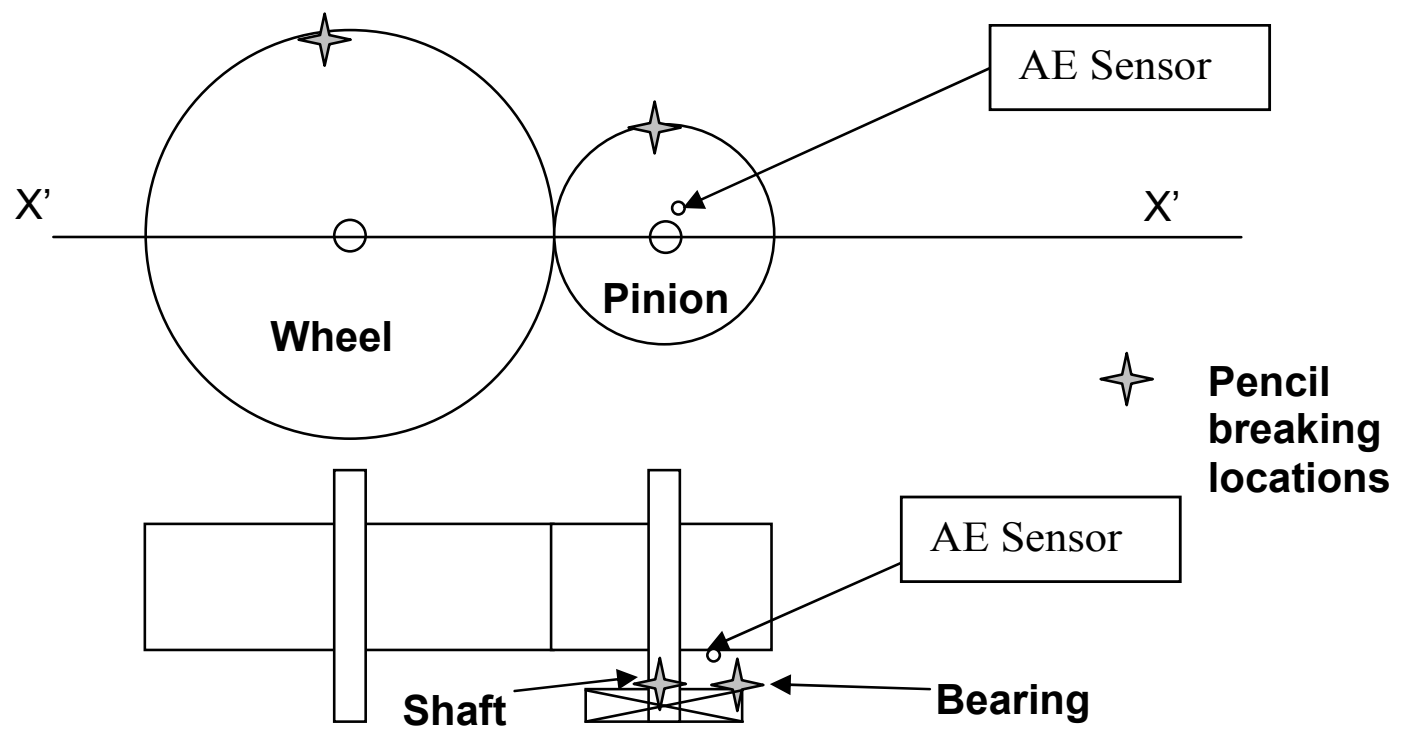

Figure 6 Schematic diagram for the attenuation test displaying different interfaces. 


\begin{tabular}{|c|c|c|}
\hline Interface & Average Amplitude & Relative Attenuation (dB) \\
\hline Bearing & 0.093 & -34.64 \\
\hline Wheel & 0.257 & -25.90 \\
\hline Pinion & 1.829 & -8.86 \\
\hline Shaft & 2.120 & -7.58 \\
\hline & & \\
\hline Reference Position & 5.074 & 0 \\
\hline
\end{tabular}

Table $1 \quad$ Relative attenuation values

\section{Results of operational background noise}

The application of AE to gear diagnostics is considered to be relatively new. Although there are many AE analysis techniques available, selection of a robust technique is of paramount importance if $\mathrm{AE}$ is to gain acceptability as a diagnostic tool.

Figure 7 displays a typical AE signature with corresponding frequency spectrum associated with operational noise. It clearly shows 16 meshing teeth that included the defective tooth. This is the first known published document that presents the gear meshing $\mathrm{AE}$ transient response in the time domain. The frequency range of the $\mathrm{AE}$ signals associated with these tests ranged from $75 \mathrm{kHz}$ to $350 \mathrm{kHz}$. Figures 8 and 9 illustrate the time domain signatures for the load and speed cases considered. The gear mesh frequency can also be calculated from the time domain AE signal by inversing the periodic time between two subsequent AE burst. It must be noted that at 1460rpm the AE bursts associated with the gear mesh was not as clearly visible as at $745 \mathrm{rpm}$. This 
was principally due to the limit of sampling frequency on the acquisition system. At a faster sampling rate it would be expected that the AE bursts associated with the gear mesh at 1460rpm will be clearly visible.

For analysis of AE data obtained from these experiments, r.m.s and energy were not only employed to provide a comparison to other published work but principally because of the simplicity and proven robustness of these parameters for machine health diagnosis. In addition, the calculation of crest factor on the same AE data allowed the authors to understand some of the characteristics of the AE signatures.
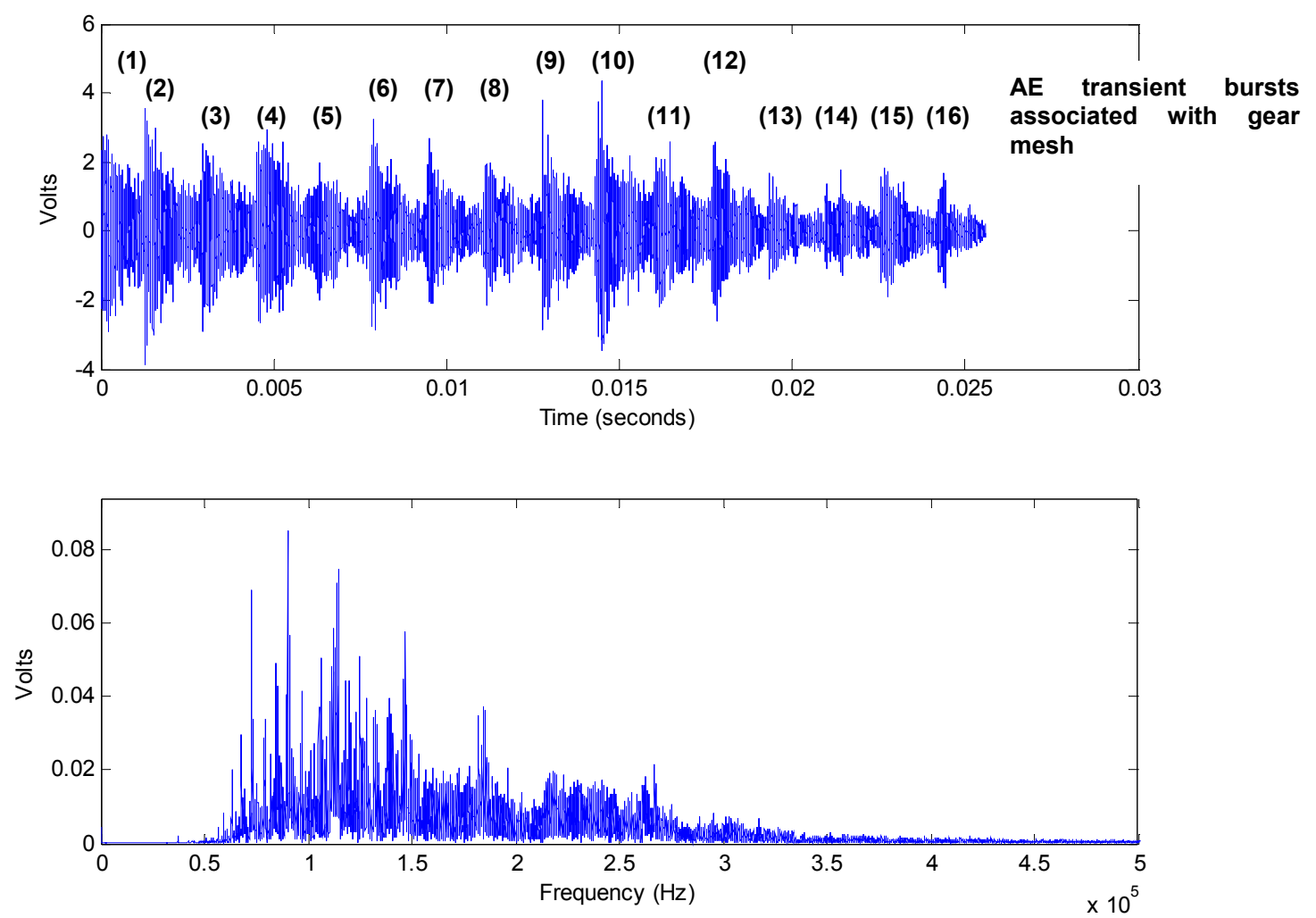

Figure 7 Time and frequency domain of an AE signature showing clearly the AE transient response associated with gear meshing of 16 teeth for the rotational speed of $745 \mathrm{rpm}$ (pre-amplification $40 \mathrm{~dB}, 110 \mathrm{Nm}$ ) 

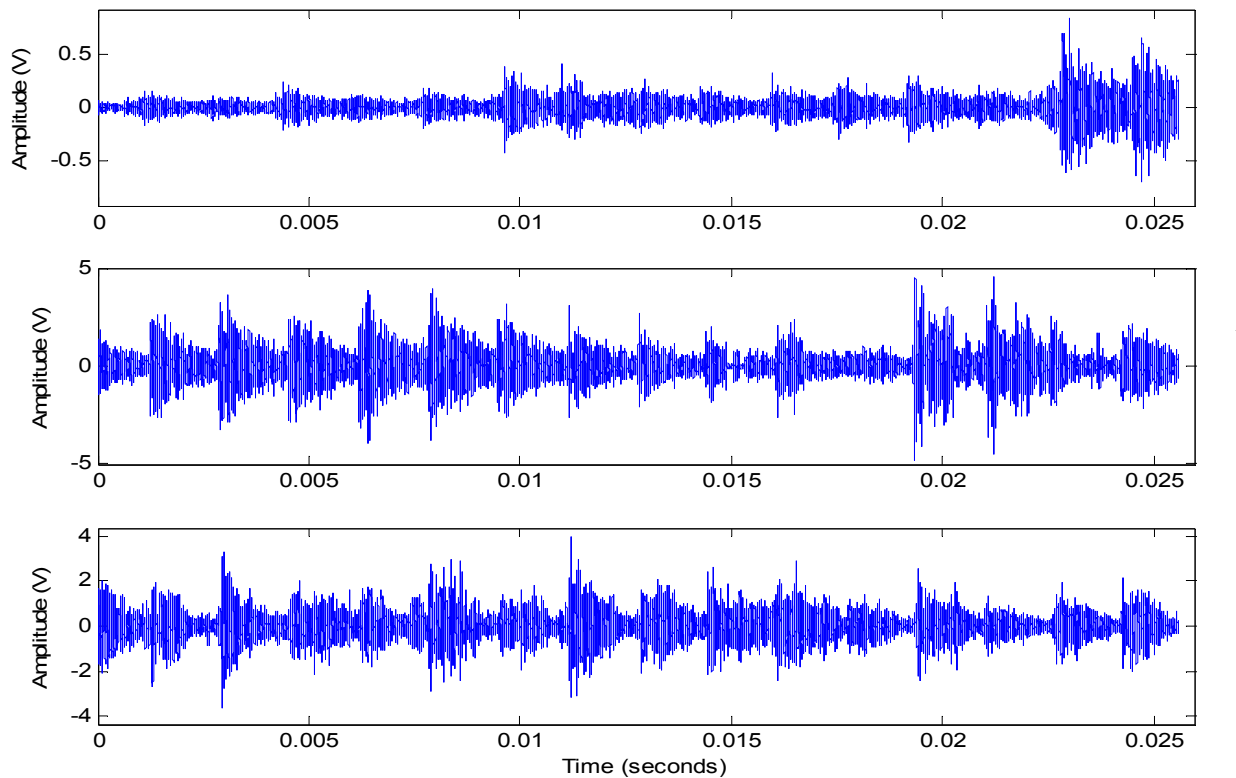

Figure 8 Raw AE signal for large addendum defect for (a) no load, (b) $55 \mathrm{Nm}$ load and (c) $110 \mathrm{Nm}$ load at $745 \mathrm{rpm}$ (pre-amplification 40dB)
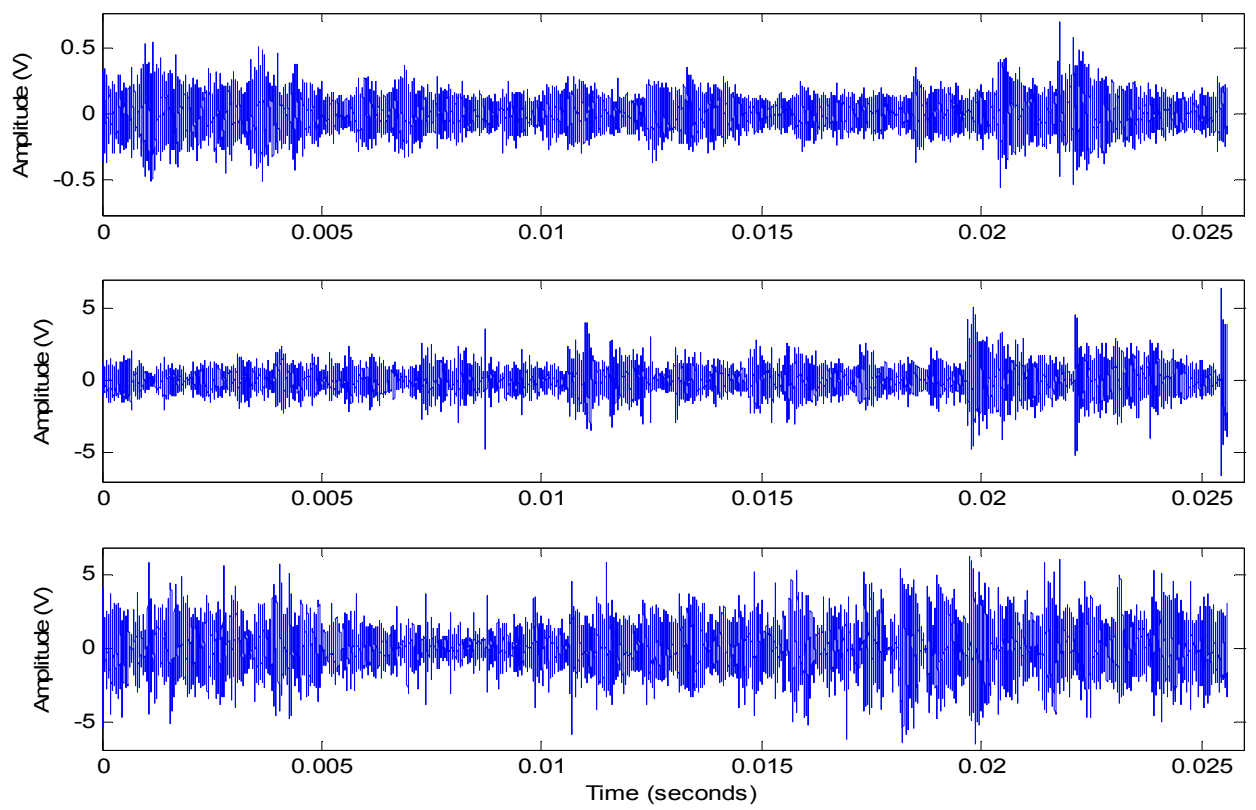

c

Figure 9 Raw AE signal for large addendum defect for (a) no load, (b) $55 \mathrm{Nm}$ load and (c) $110 \mathrm{Nm}$ load at $1460 \mathrm{rpm}$ (pre-amplification 40dB) 


\section{Results of defect simulations}

For the rotational speeds of 745 and $1460 \mathrm{rpm}$, the recorded AE time waveform was divided into five and ten different regions respectively, with each region representing 3teeth, figure 5 illustrated the case of $745 \mathrm{rpm}$. The r.m.s. value of each region was computed and plotted against the three loading conditions. It was thought that this method of grouping the data would enhance the possibilities of detecting the seeded defect particularly as the defect has been seeded in the centre of the acquisition window. A total of 50 data sets, each equivalent to a time frame encompassing sixteen teeth, were acquired and averaged in each region. The averaging could be accomplished due to the optical triggering system employed ensuring that the acquisition system always started at the same rotational position of the gears.

For the seeded defect simulation at $745 \mathrm{rpm}$, the r.m.s. values remained random for the three loading conditions, see figure 10 , as no definite trend was observed. The centre region ' 3 ', where the seeded defect was introduced, did not exhibit the highest r.m.s. value as expected. Similar observations were made for the rotational speed of $1460 \mathrm{rpm}$, the highest r.m.s. value did not occur at the seeded fault region (region ' 5 '), see figure 11. 


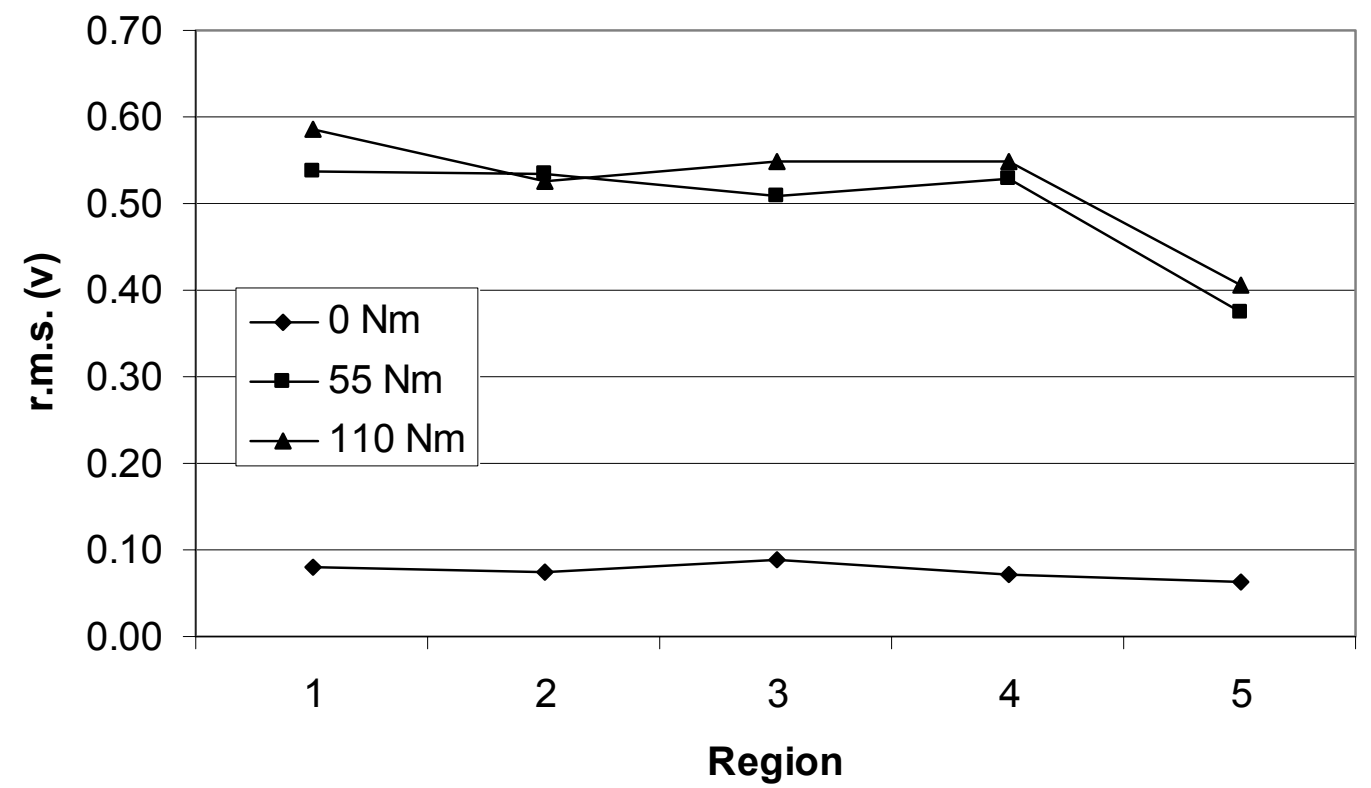

Figure $10 \quad$ r.m.s against loads for 3-teeth analysis at $745 \mathrm{rpm}$. (5 regions)

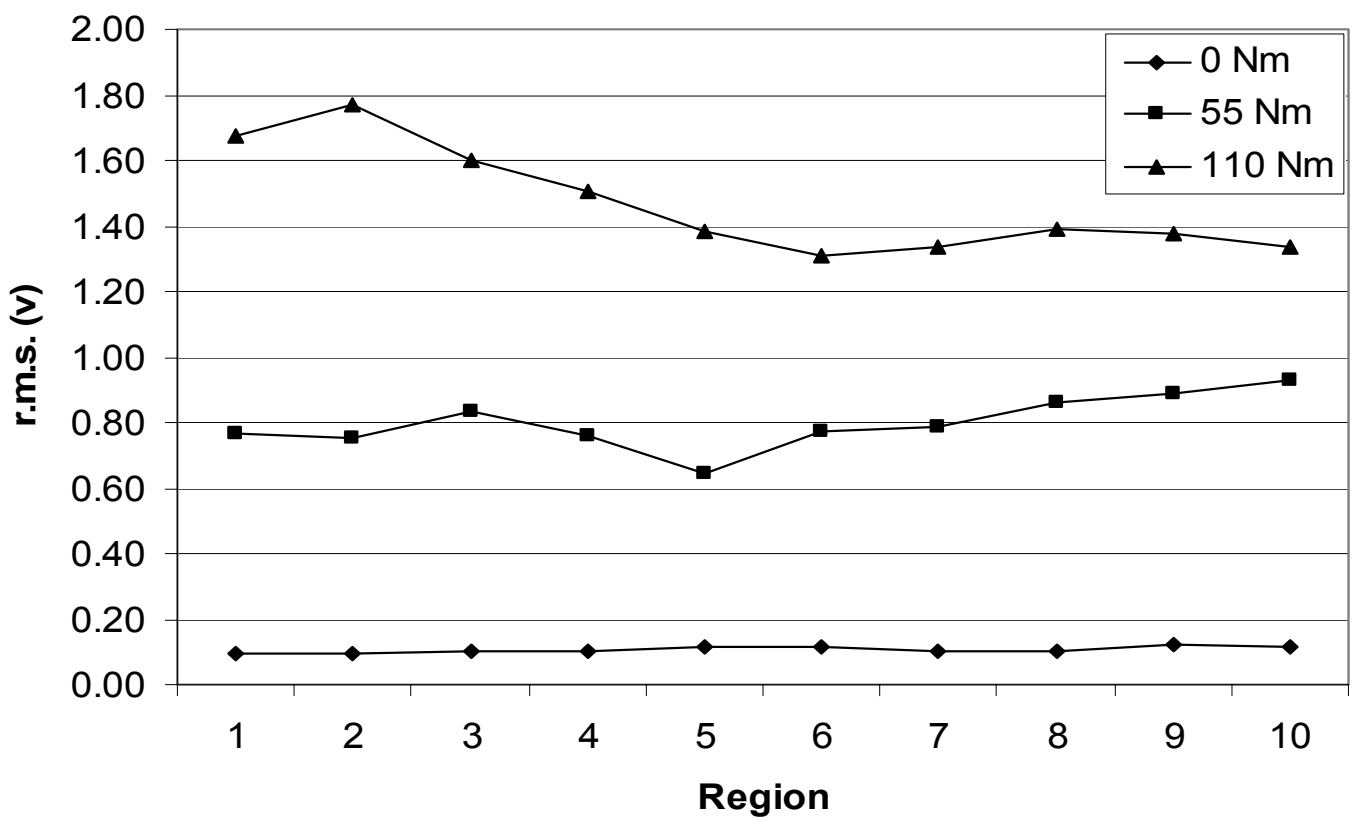

Figure 11 r.m.s against loads for 3-teeth analysis at $1460 \mathrm{rpm}$. (10 regions) 
In order to confirm the authenticity of these results the recorded AE data was split further into regions representing 2-teeth and 1-tooth for the rotational speed of 745 and $1460 \mathrm{rpm}$ respectively. The r.m.s. value of each region was computed and plotted against the three load conditions for the defect condition, see figures 12 to 15 . For the 2teeth analysis, figures 12 and 13, it was observed that the maximum r.m.s. values did not occur at regions '4' and ' 8 ' for 745 and 1460 rpm respectively. From figures 14 and 15 , similar observations were noted, the r.m.s. values at the seeded fault tooth, regions ' 8 ' and ' 15 ' (based on a single tooth demarcation for 745 and $1460 \mathrm{rpm}$ respectively), were not the highest values. The inconsistency between the single tooth, 2-teeth and 3teeth analysis for both speed conditions revealed that this technique was inconsistent for defect identification. The results would have been conclusive had the r.m.s. levels for the defective tooth being higher than other regions within the acquisition window. For the same test condition, AE energy exhibited similar observations see figures 16 to 21 .

The raw AE signals from defect conditions are displayed in figures 8 and 9. This shows the non-consistent observation of $\mathrm{AE}$ burst in relation to the defect position. The biggest burst of the AE signal did not always occur in the centre region of the window where the seed fault was located even though the defect was comparatively large. Hence, it was not possible to detect the seeded defect using the AE indicators of r.m.s. and energy. This contradicts the work of a few researchers $[6,9,10]$ that claimed $\mathrm{AE}$ indicators could clearly identify a simulated pit defect.

Some interesting observations were noted from figures 10 to 15 . Firstly, at $745 \mathrm{rpm}$ for the 1-, 2- and 3- teeth analysis, the r.m.s. values for the three load conditions varied 
from 0.1 to 0.6 volts whilst at the higher speed, r.m.s. values varied from 0.1 to 1.8 volts. Secondly, it was noted that the r.m.s. values for the unloaded conditions at both speeds are similar. In general, the r.m.s. values increased with increasing load conditions. It was observed that the loaded conditions at $745 \mathrm{rpm}$ had similar r.m.s. values whereas at $1460 \mathrm{rpm}$ the r.m.s. values were distinctly different. Average r.m.s. and energy values for all the test conditions were calculated and plotted in figures 22 and 23 , reiterating observations between r.m.s., load and speed.

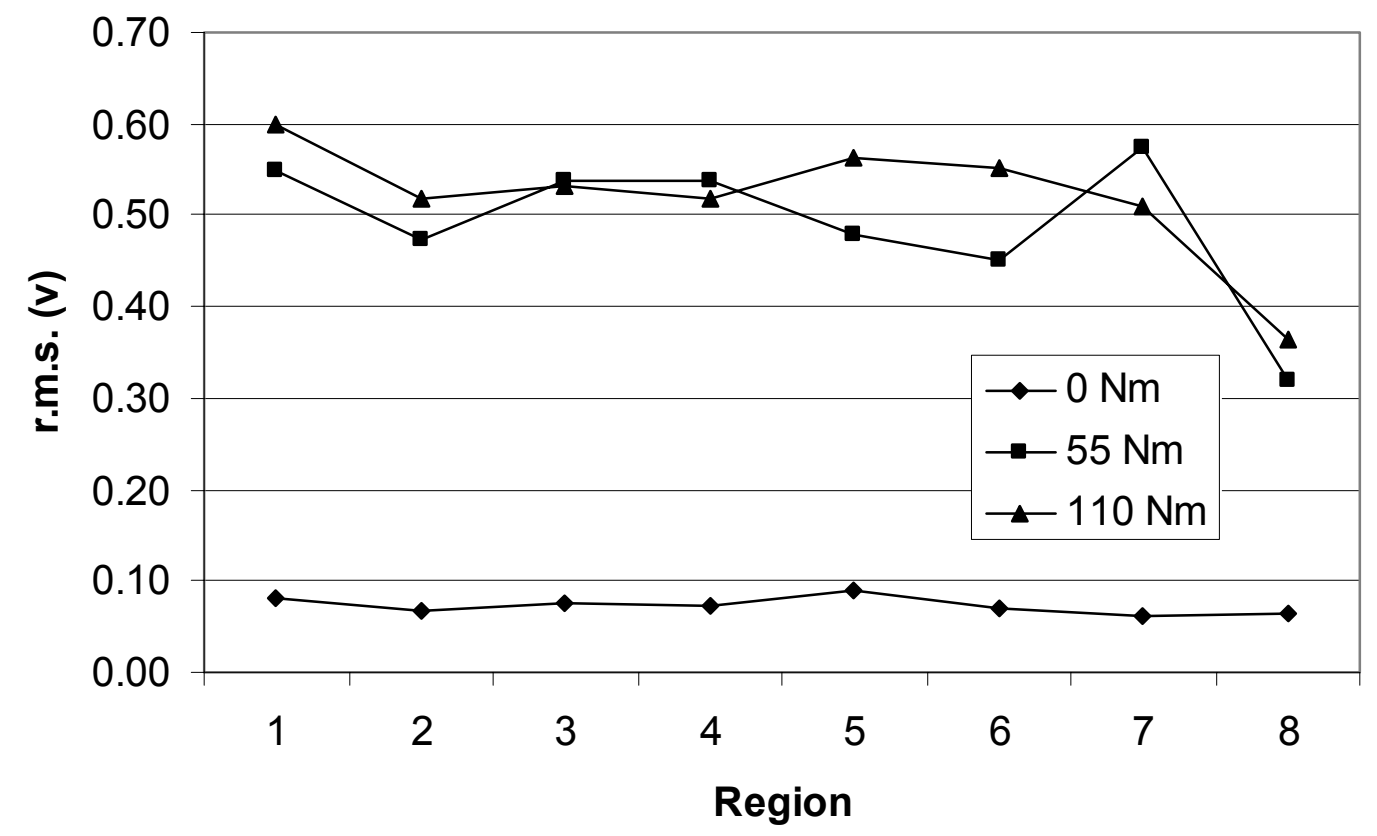

Figure 12 r.m.s against loads for 2-teeth analysis at $745 \mathrm{rpm}$. (8 regions) 


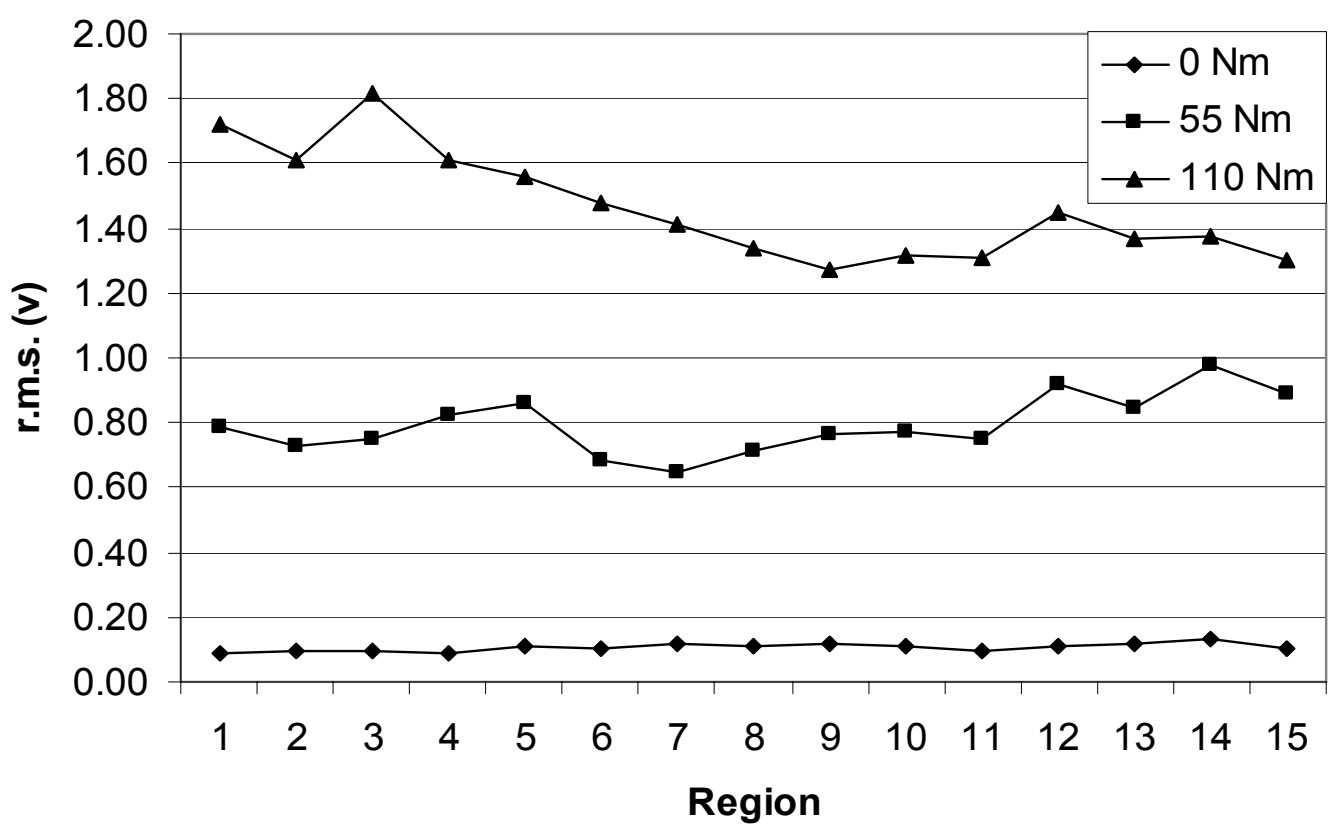

Figure $13 \quad$ r.m.s against loads for 2-teeth analysis at $1460 \mathrm{rpm}$. (15 regions)

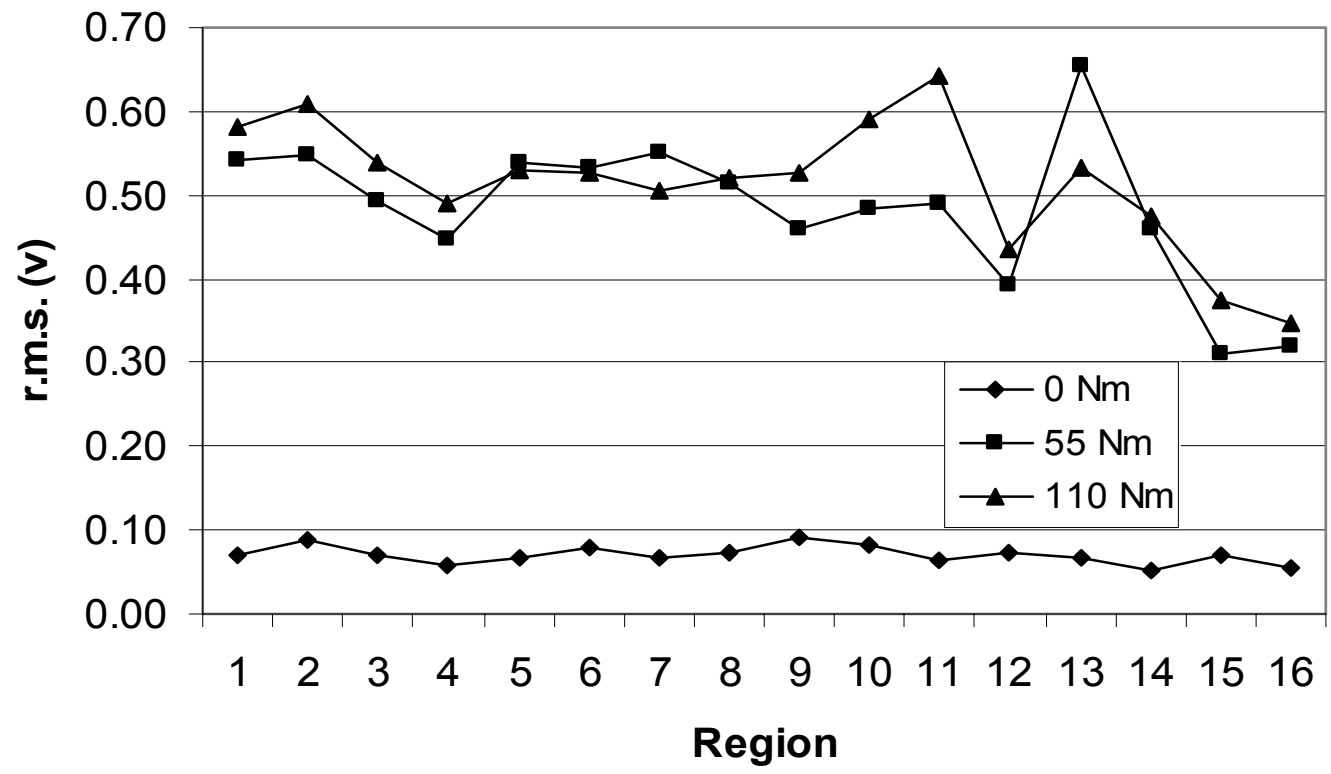

Figure 14 r.m.s against loads for 1-tooth analysis at $745 \mathrm{rpm}$. (16 regions) 


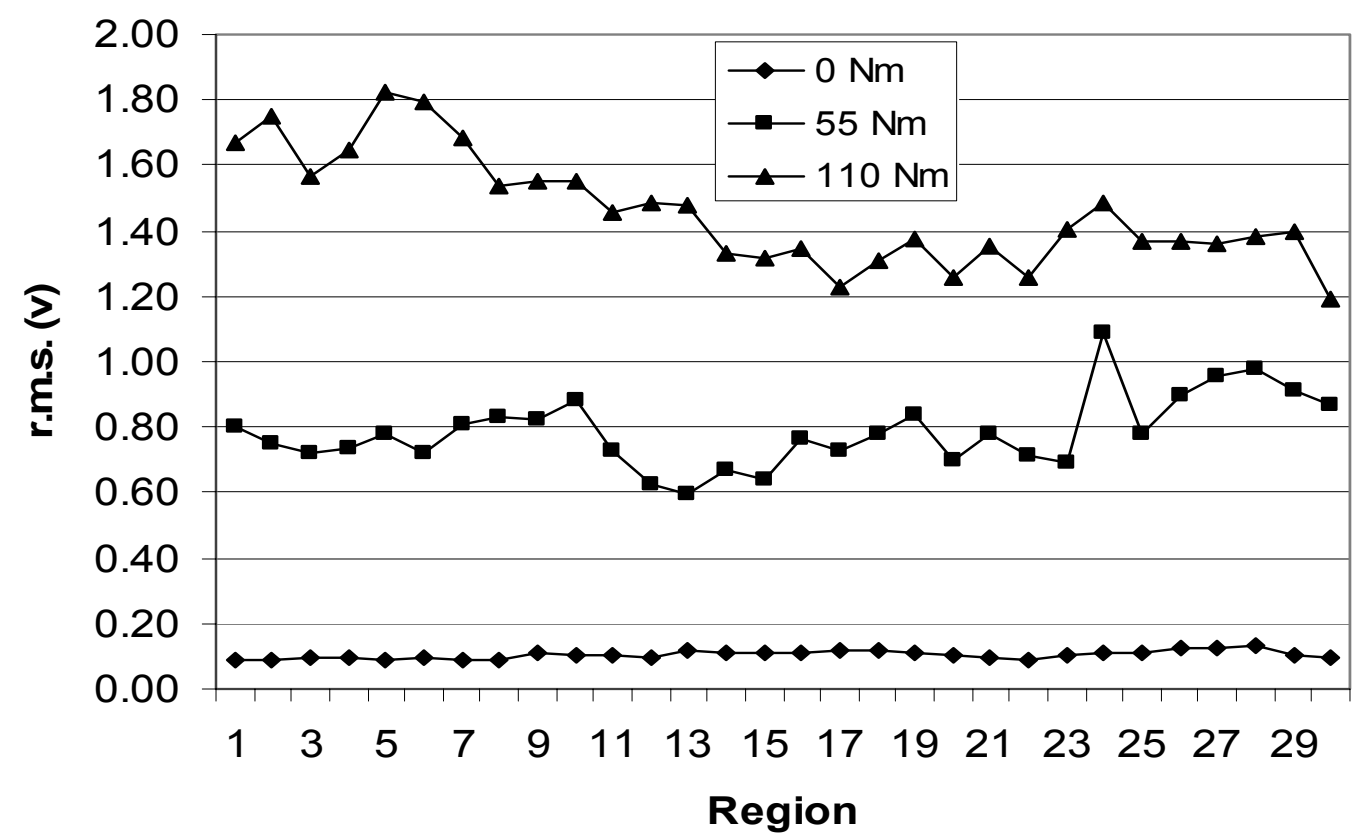

Figure 15 r.m.s against loads for 1-tooth analysis at $1460 \mathrm{rpm}$. (30 regions)

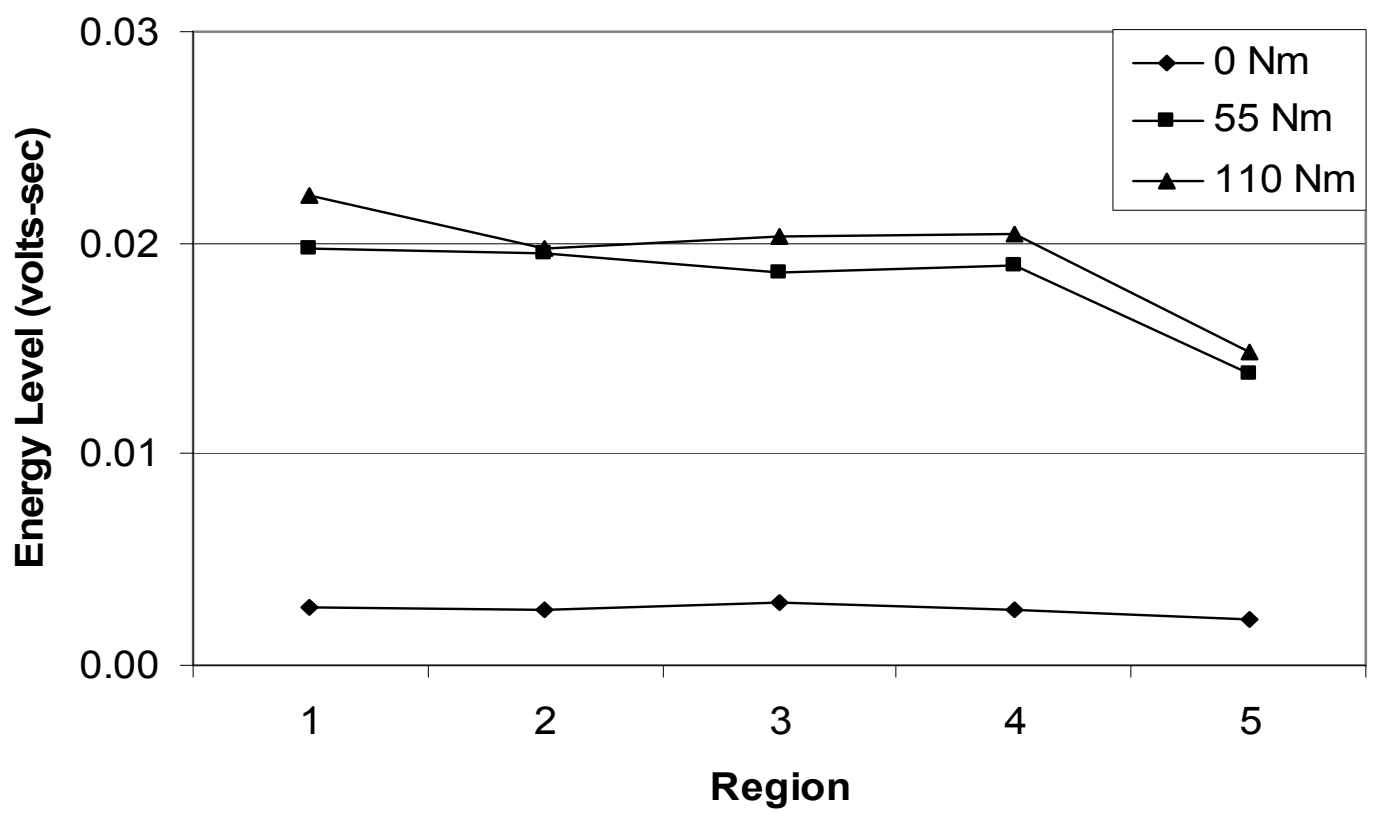

Figure 16 AE energy level is not the highest in region 3, where seeded defect was introduced for 3-teeth analysis at $745 \mathrm{rpm}$. (5 regions) 


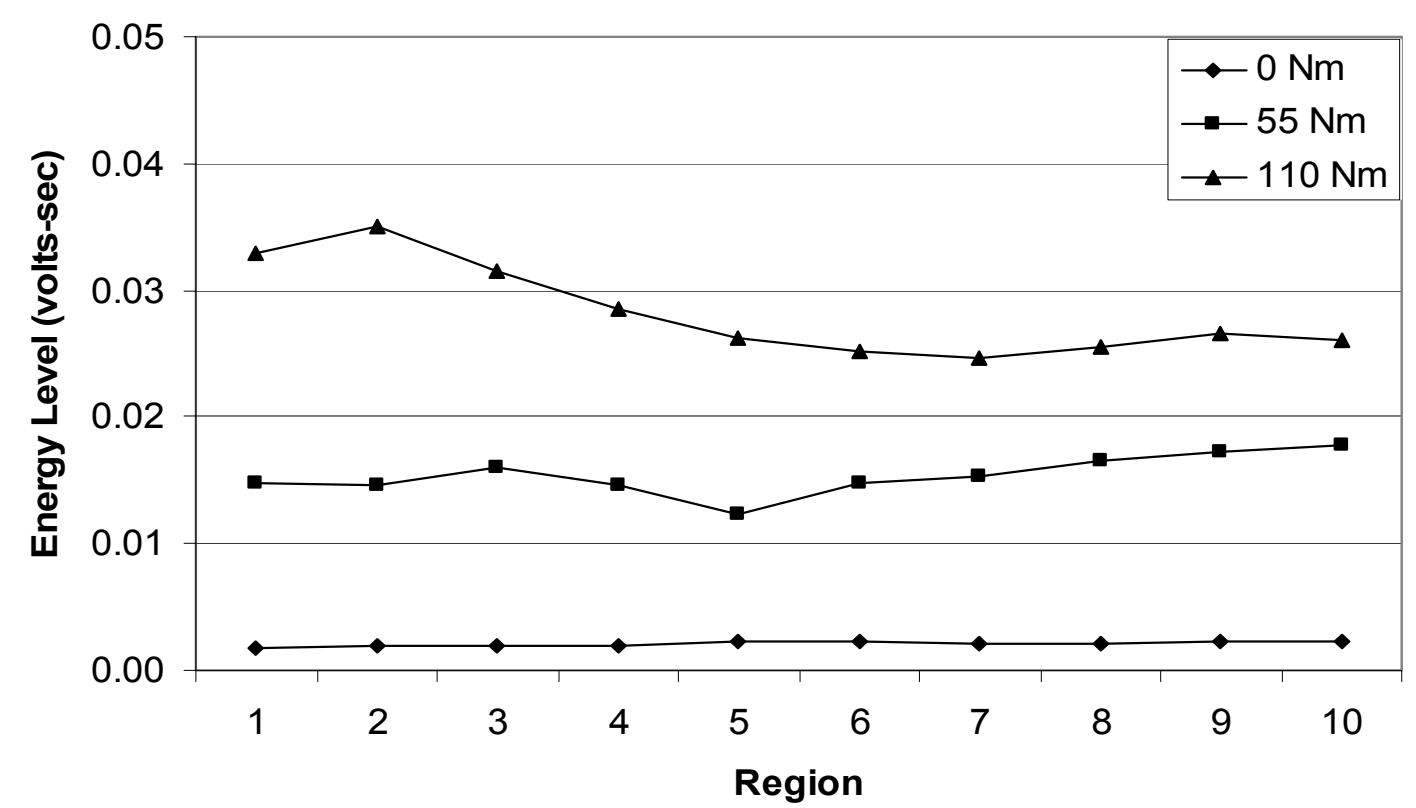

Figure 17 AE energy level is highest in region 5, where seeded defect was introduced for 3-teeth analysis at $1460 \mathrm{rpm}$. (10 regions)

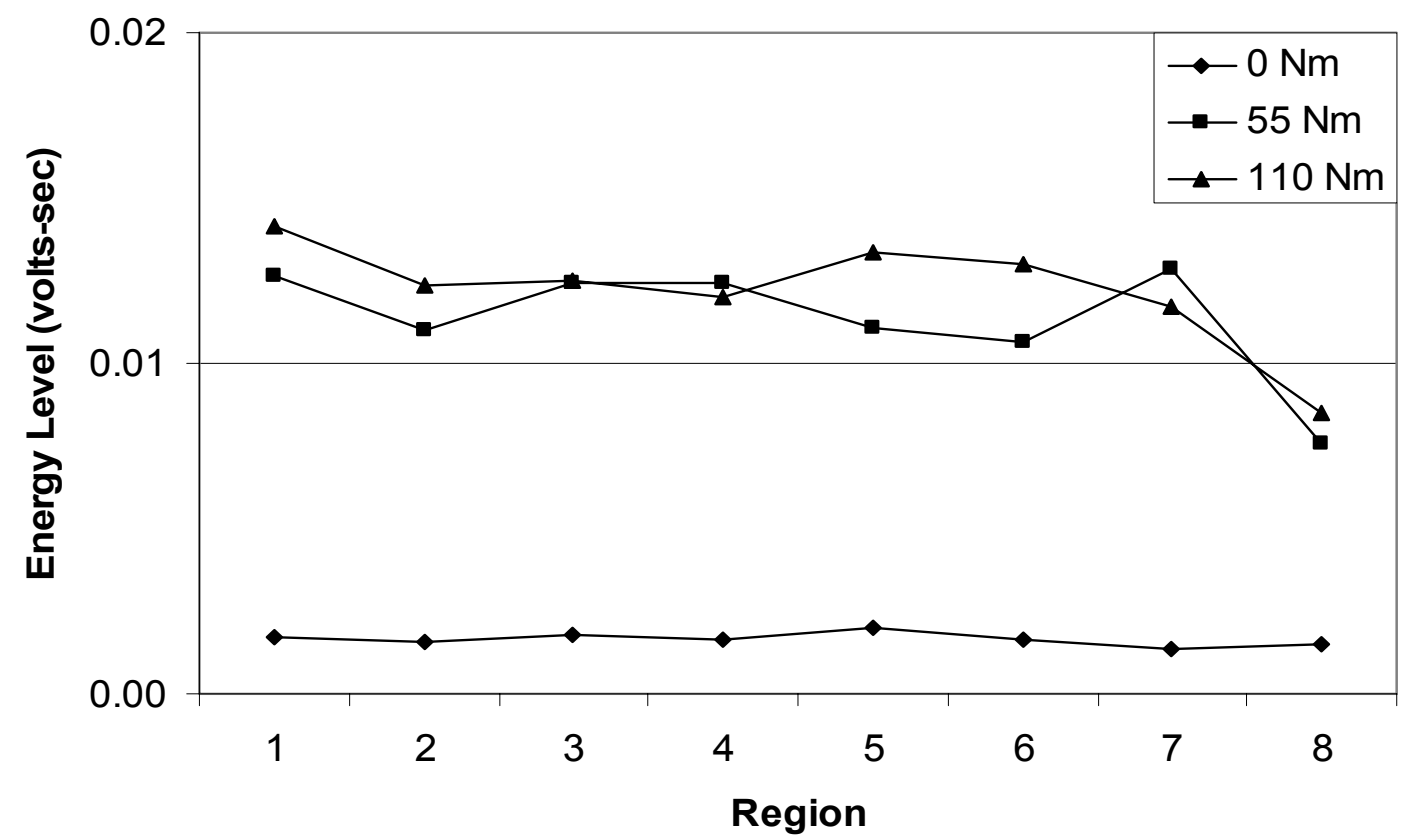

Figure 18 The highest AE energy level is not in the seeded defect region, region 4 , for 2-teeth analysis at $745 \mathrm{rpm}$. (8 regions) 


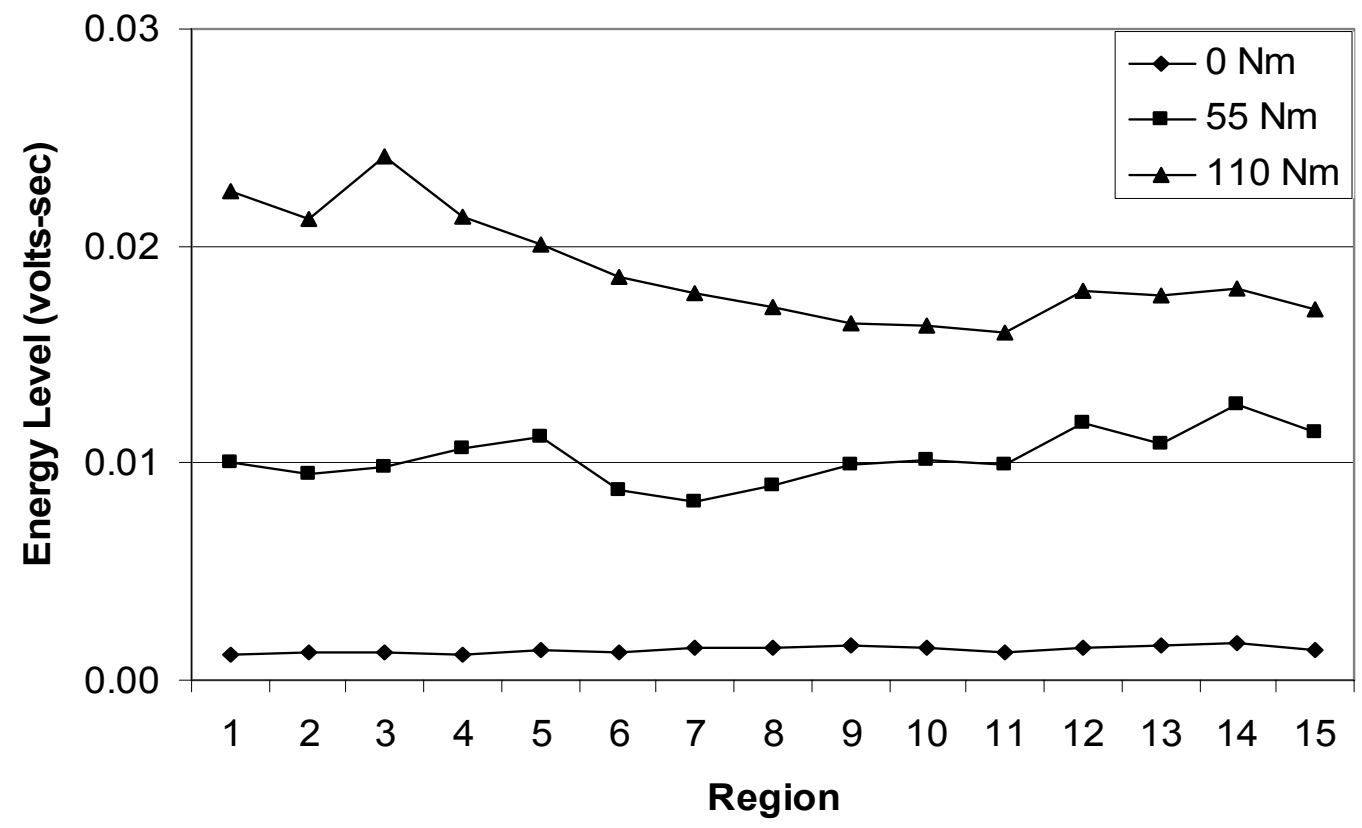

Figure 19 The highest AE energy level is not in the seeded defect region, region 8, for 2-teeth analysis at $1460 \mathrm{rpm}$. (15 regions)

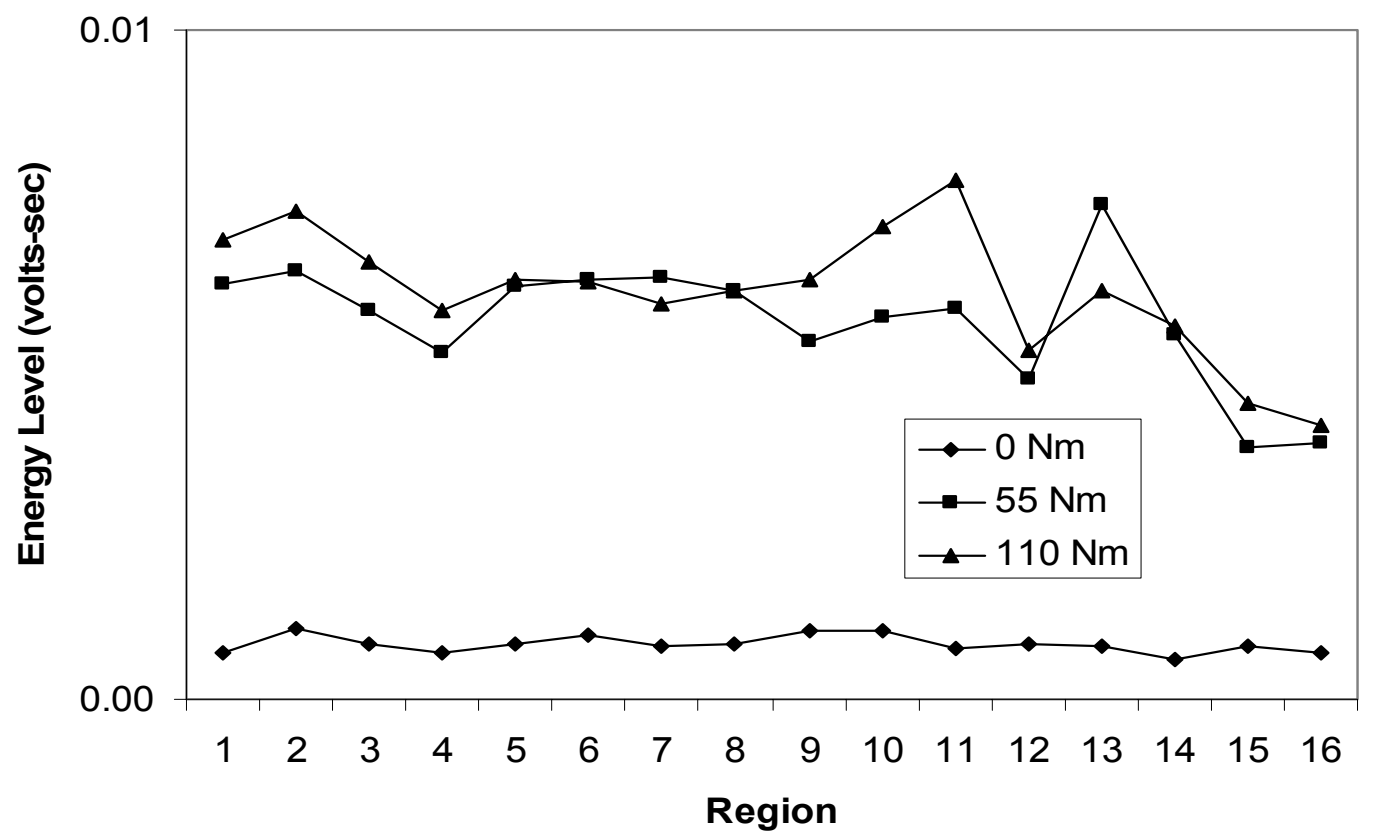

Figure 20 The highest $\mathrm{AE}$ energy level is not in the seeded defect region, region 8, for 1-tooth analysis at $745 \mathrm{rpm}$. (16 regions) 


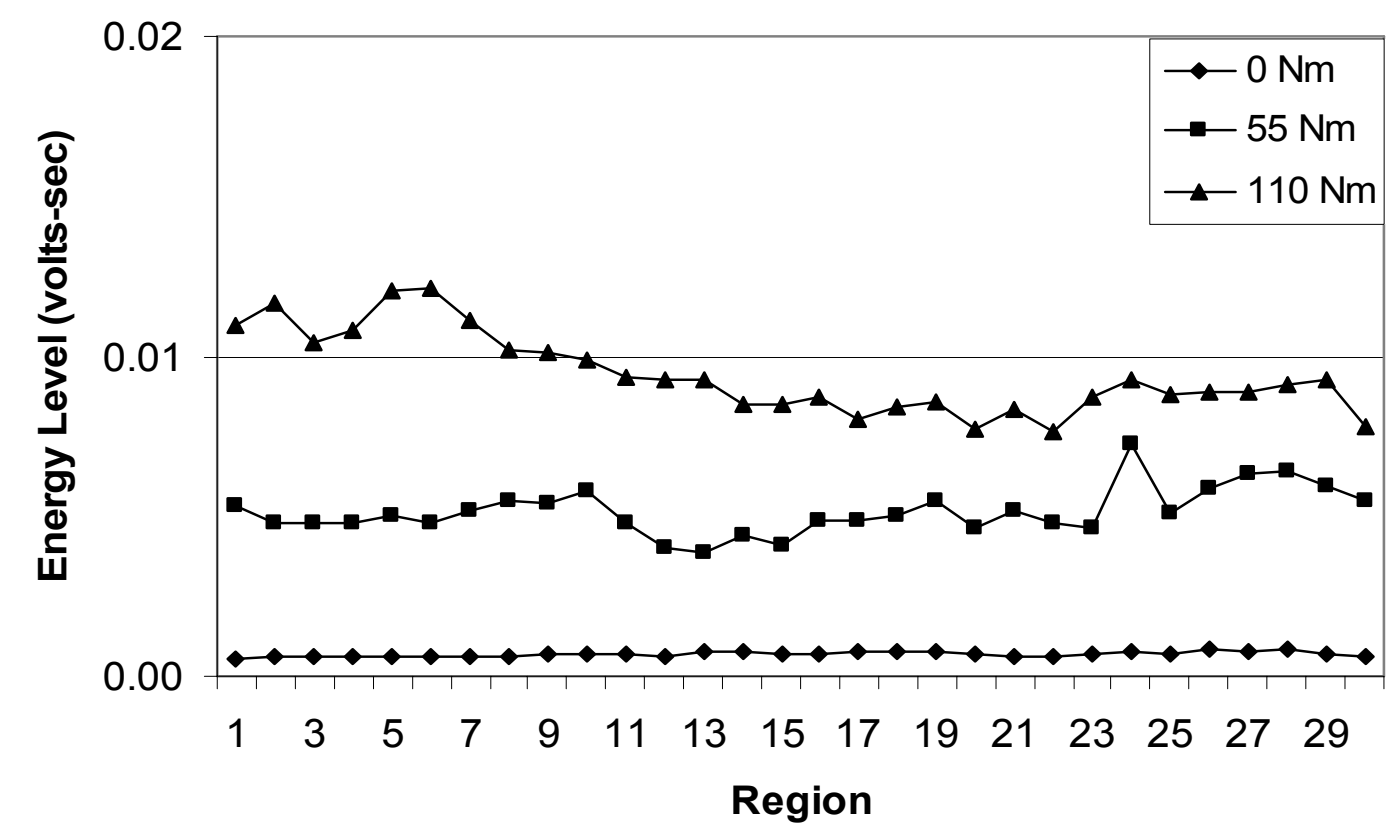

Figure 21 The highest $\mathrm{AE}$ energy level is not in the seeded defect region, region 15, for 1-tooth analysis at $1460 \mathrm{rpm}$. (30 regions)

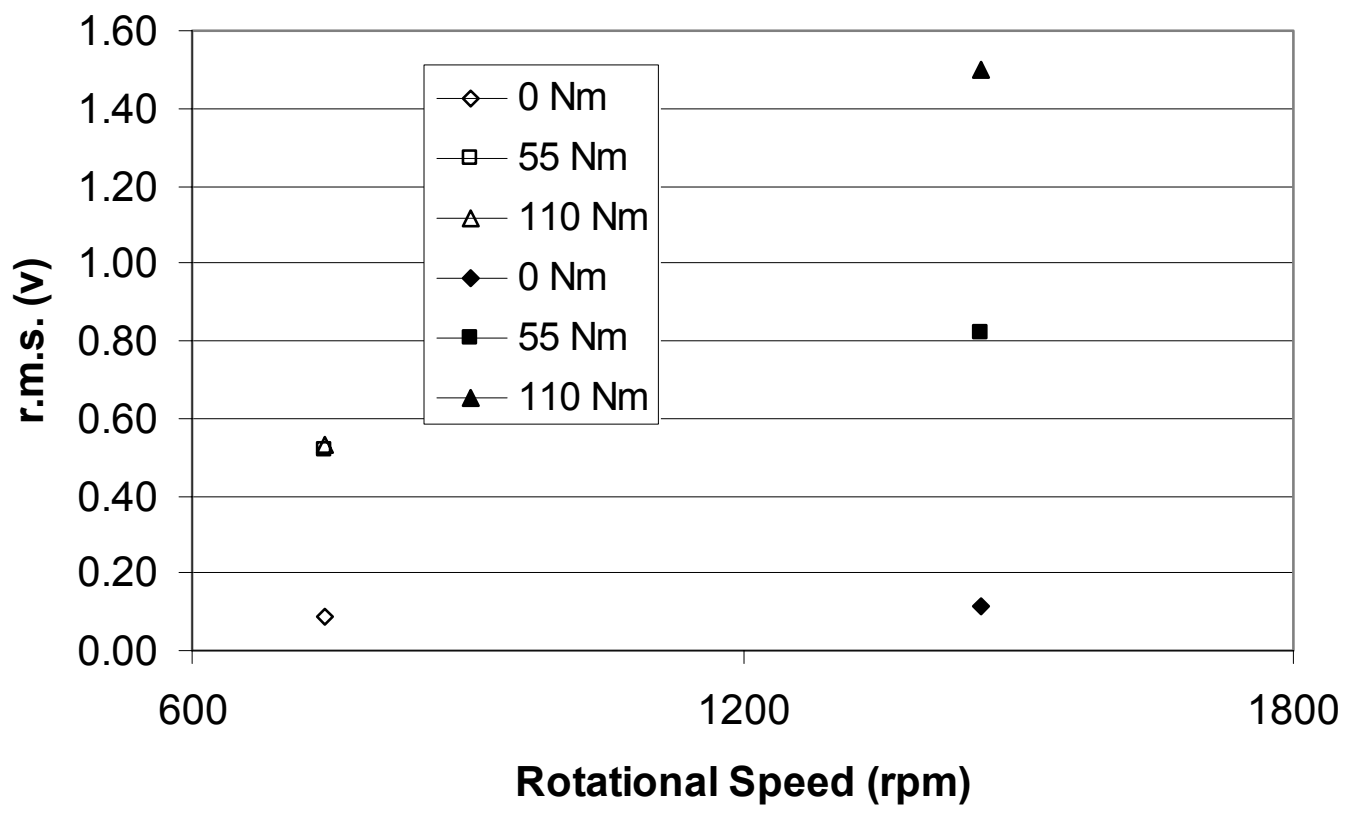

Figure 22 Overall r.m.s. values for the six test conditions. 


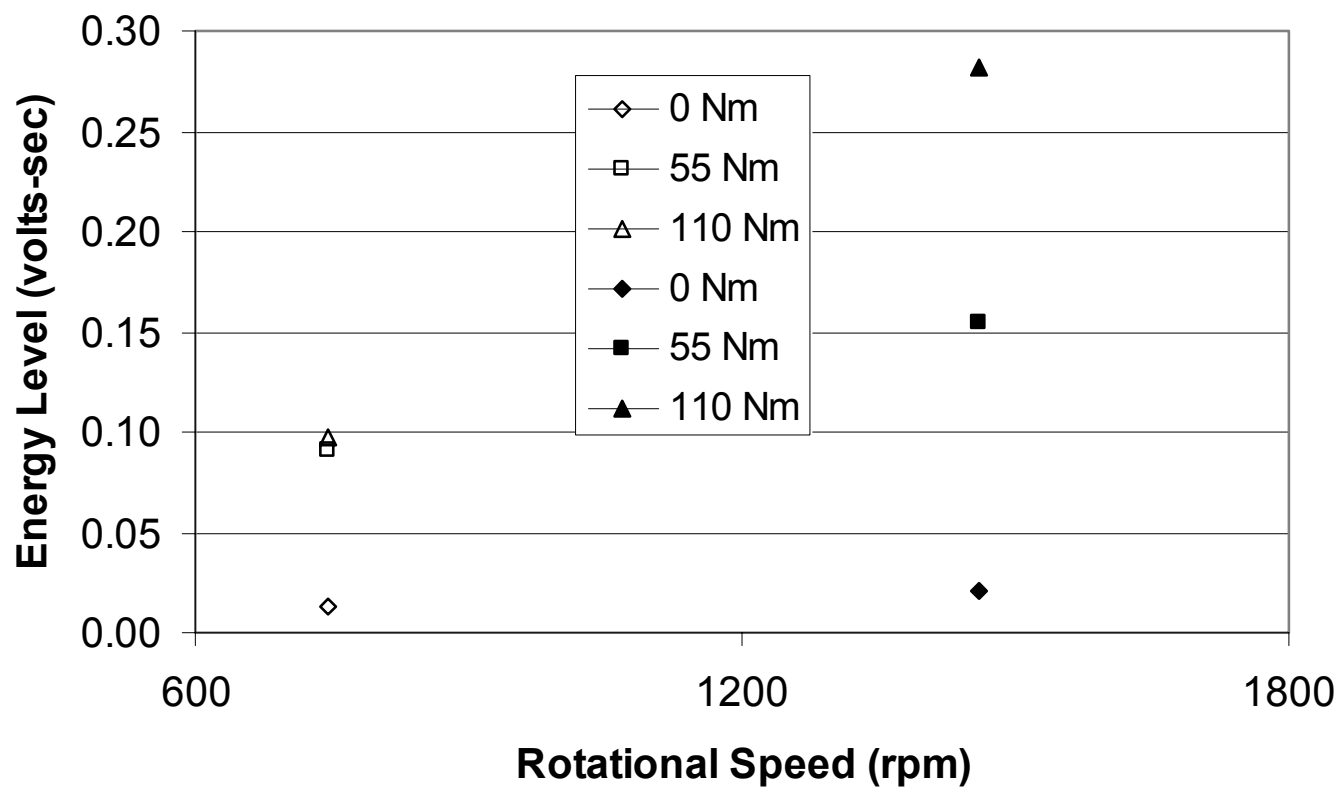

Figure 23 Overall energy levels for the six test conditions.

\section{Observations of crest factor}

Crest factor is a measure of ratio between peak value and r.m.s. of the AE signal. The crest factor was computed per data file and averaged over fifty data files per simulation. The crest factor for the defect conditions under the various load and speed combinations can be seen in figure 24. It was observed that the crest factor decreased with increased load for both speed conditions. The crest factors at $745 \mathrm{rpm}$ were always higher than those of $1460 \mathrm{rpm}$ for the corresponding load conditions. In order to understand these observations, the peak amplitude values for the same test conditions were computed and plotted in figure 25. For both speed conditions, the peak amplitude increased with increased load except for $110 \mathrm{Nm}$ at $745 \mathrm{rpm}$. 


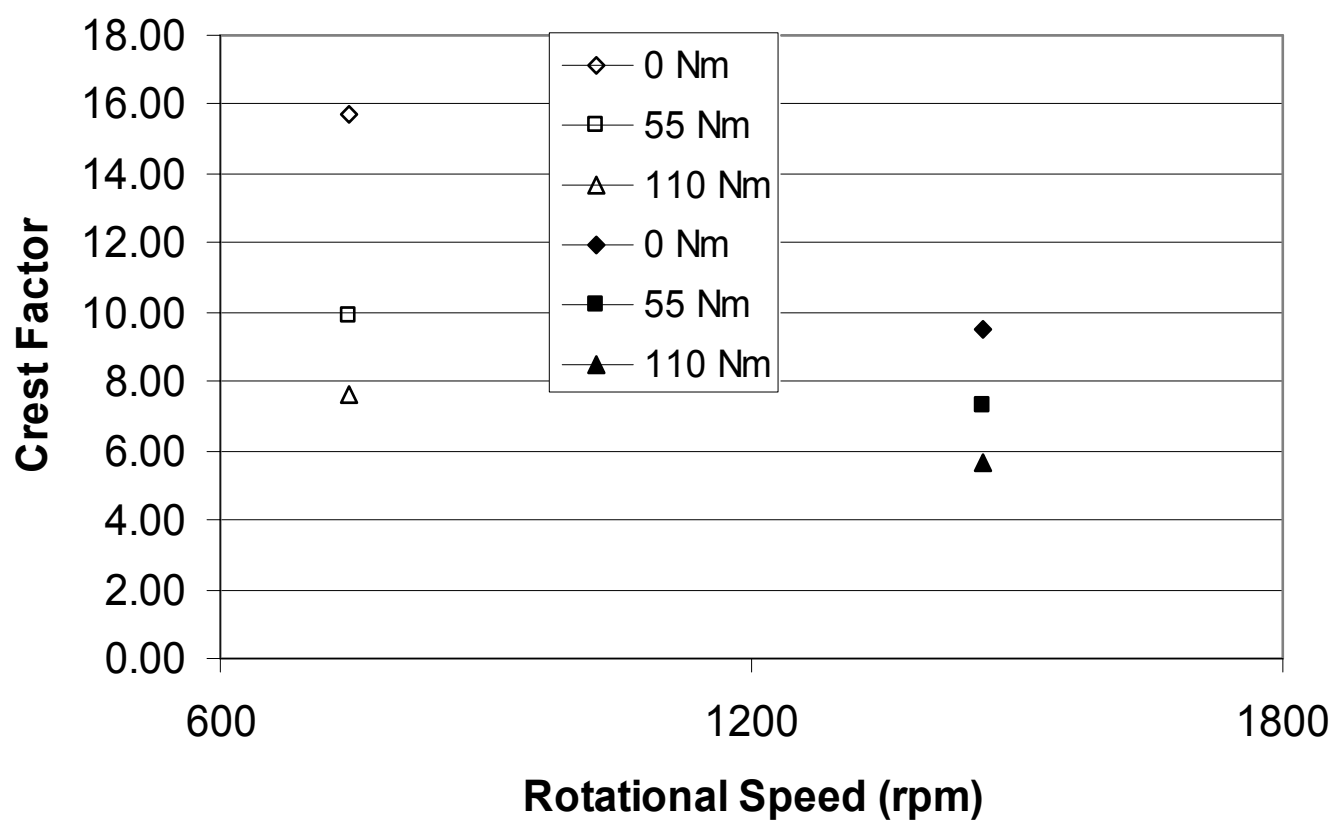

Figure 24 Crest factors for the six test conditions.

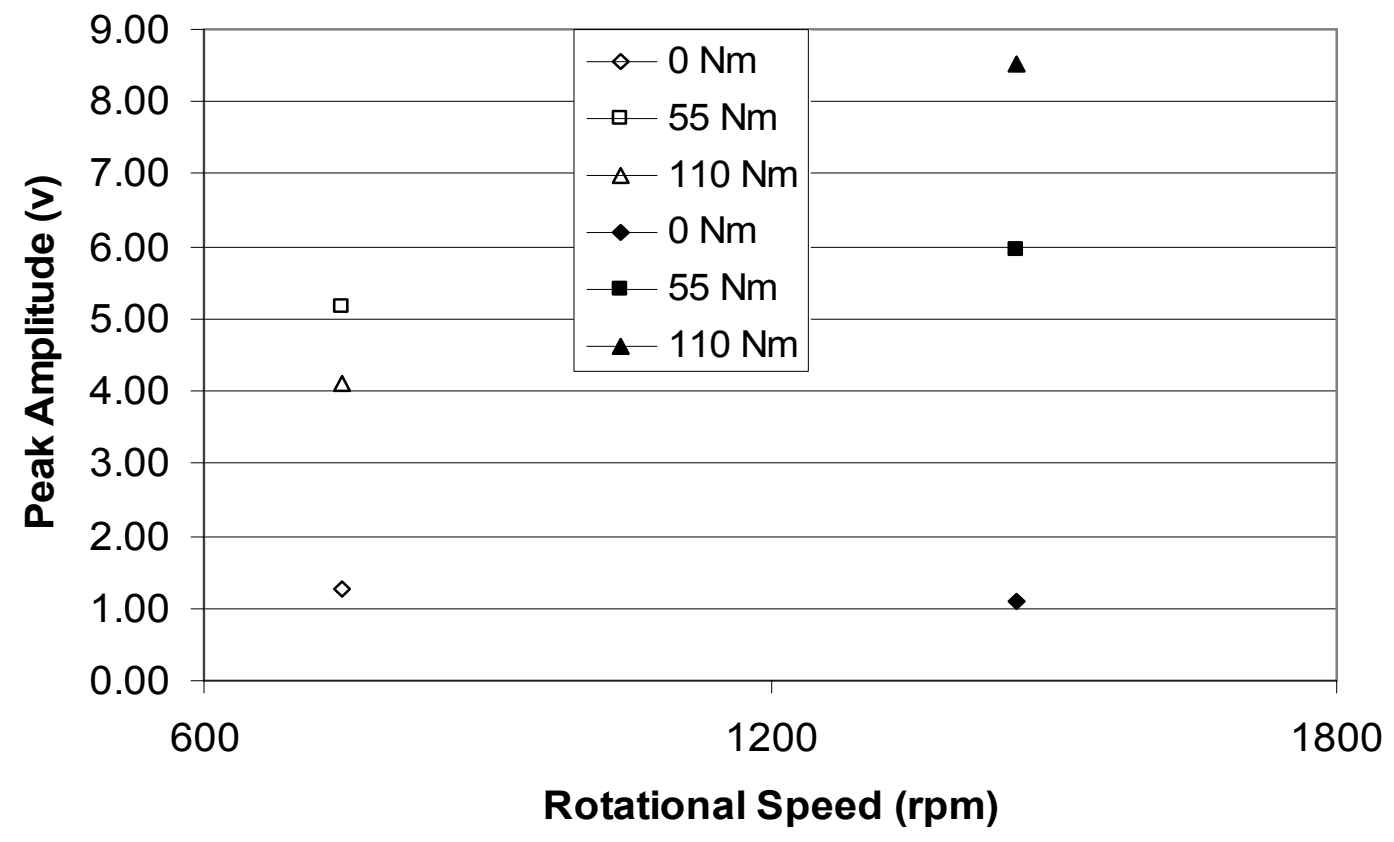

Figure 25 Peak Amplitudes for the six test conditions. 
From figures 22 and 24, it was observed that crest factor decreased with increasing load while r.m.s values increased with increasing load at 745 and $1460 \mathrm{rpm}$. Table 2 provides the detailed changes in r.m.s values and peak amplitude at $745 \mathrm{rpm}$. From 0 to $55 \mathrm{Nm}$ load, the r.m.s value increased more than the peak amplitude which gave an overall decrease in crest factor. From 55 to $110 \mathrm{Nm}$ load, the peak amplitude decreased much more than the increase in r.m.s. which provide an overall effect of reducing the crest factor. However, as the load was increased from 55 to $110 \mathrm{Nm}$, only a slight increase in r.m.s. was observed with a reduction in peak amplitude. The exact reason for this was unclear at this stage of the investigation. It was expected that the peak amplitude and r.m.s. would increase with increasing load.

\begin{tabular}{|c|c|c|c|c|}
\hline & Peak Amplitude (v) & \% change & r.m.s. (v) & \% change \\
\hline $\mathbf{0 ~ N m}$ & 1.2806 & - & 0.0887 & - \\
\hline $\mathbf{5 5} \mathbf{~ N m}$ & 5.1744 & $+304 \%$ & 0.5158 & $+482 \%$ \\
\hline $\mathbf{1 1 0} \mathbf{~ N m}$ & 4.0915 & $\mathbf{- 2 1 \%}$ & 0.5328 & $+3 \%$ \\
\hline
\end{tabular}

Table 2 Percentage difference in peak amplitude and r.m.s. at 745 rpm.

At $1460 \mathrm{rpm}$, it was observed that as the r.m.s. increased, the crest factor decreased with an increase in load, see figures 22 and 24. For this condition to exist, the peak amplitudes must either be constant, decrease or increase to a lesser extent than r.m.s. values. From table 3, it became apparent that r.m.s. values increased more than the peak amplitudes when the load was increased incrementally to $110 \mathrm{Nm}$. 


\begin{tabular}{|c|c|c|c|c|}
\hline & Peak Amplitude (v) & \% change & r.m.s. (v) & \% change \\
\hline $\mathbf{0 ~ N m}$ & 1.0956 & - & 0.1149 & - \\
\hline $\mathbf{5 5} \mathbf{~ N m}$ & 5.9511 & $+443 \%$ & 0.8195 & $+\mathbf{6 1 3 \%}$ \\
\hline $\mathbf{1 1 0} \mathbf{~ N m}$ & 8.5040 & $+43 \%$ & 1.5022 & $+\mathbf{8 3 \%}$ \\
\hline
\end{tabular}

Table 3 Percentage difference in peak amplitude and r.m.s. at $1460 \mathrm{rpm}$.

In general, it was observed that increasing the load resulted in an increase in AE peak amplitude and r.m.s. values, however, the greater increase was the r.m.s. This increase in r.m.s. was interpreted as a direct consequence of the increased area for frictional contact as an increase in load will result in greater contact between meshing teeth.

\section{AE Observations from the bearing housing}

Whilst AE signatures recorded on the pinion was triggered when the defect was in the 'gear mesh window', the AE sensor on the bearing casing was synchronised with the AE sensor on the pinion. As such, when the data acquisition system was triggered, both AE sensors captured data simultaneously.

During the test, it was noted that the AE bursts relating to the gear mesh, as detected on the sensor fixed onto the pinion, were also observed from the sensor on the bearing casing, see figures 26 and 27. However, continuous observations of the AE sensor on the bearing casing showed intermediate loss of the AE bursts associated with the gear mesh. The reason for this is attributed to the position of the bearing ball/roller elements 
during rotation. It is postulated that when the ball/roller is at bottom dead centre, i.e. directly in the load path, the transmission of the AE bursts to the sensor on the bearing casing was most favourable and only under this circumstance. As the relative attenuation ranged from $44 \mathrm{~dB}$ to $26 \mathrm{~dB}$ (depending on the particular gear mesh $\mathrm{AE}$ burst, see figure 26), in addition to the high probability of loss of transmission path through the bearing, see figures 27 and 28 , the authors see identifying gear defects and monitoring gear deterioration from the bearing casing as fraught with difficulties, again contrary to other investigators $[6,9,11]$.

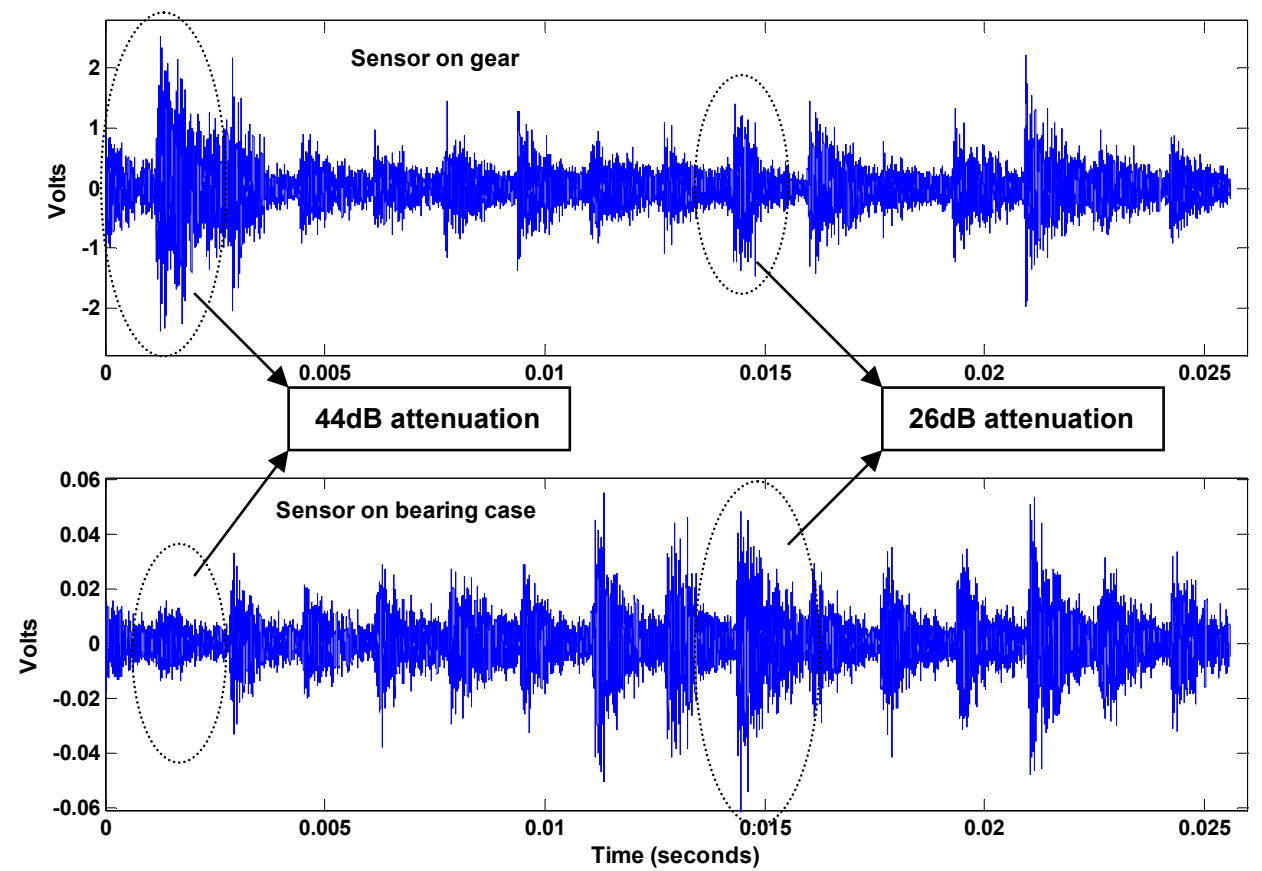

Figure 26 AE bursts detected on pinion sensor were observed on bearing casing sensor, speed $745 \mathrm{rpm}$ and load $55 \mathrm{Nm}$ (pre-amplification 40dB) 


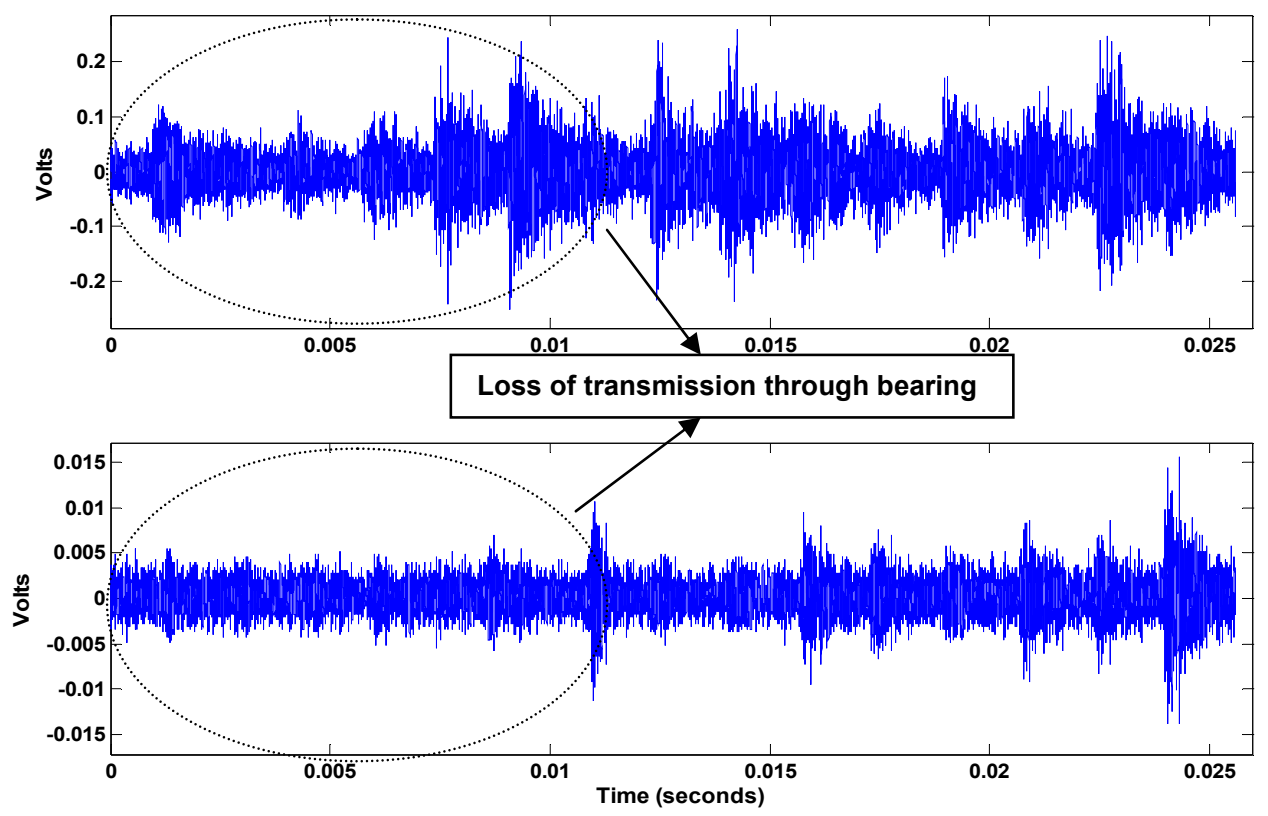

Figure 27 Loss of transmission path at particular gear mesh positions observed on bearing casing sensor, at speed $745 \mathrm{rpm}$ and load 55Nm (preamplification 20dB) 

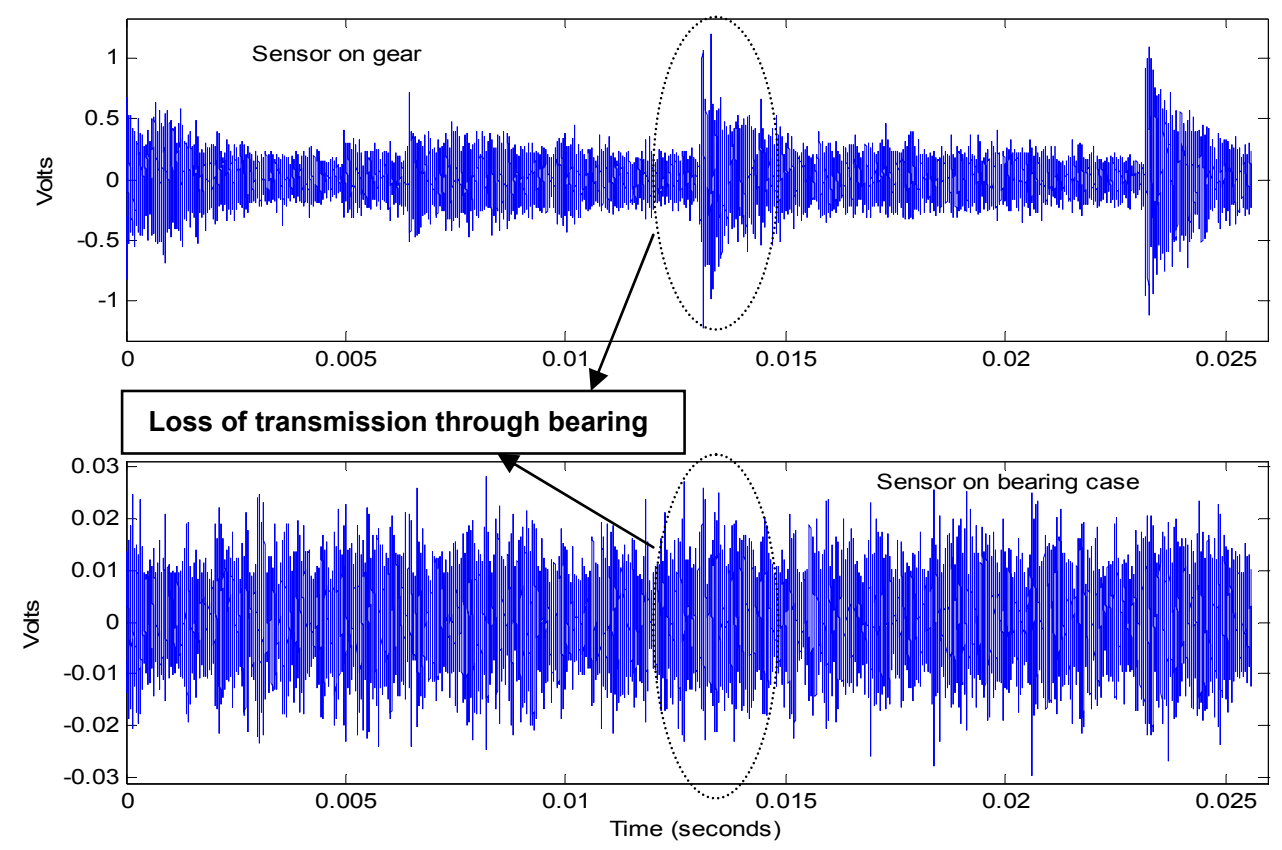

Figure 28 AE bursts detected on pinion sensor were observed on bearing casing sensor, speed $1460 \mathrm{rpm}$ and load $0 \mathrm{Nm}$ (pre-amplification 20dB)

\section{Discussions}

The relationship between AE peak amplitude and r.m.s. with load was evident. Increasing the load resulted in an increase in AE r.m.s. and peak amplitude. However, the results of AE r.m.s and energy presented thus far were considered unsatisfactory in identifying the defect location. This resulted in additional tests to explain the discrepancies, particularly as other authors had supported the applicability of these parameters to gear defect detection. The objective of the new test was to establish if operating conditions such as the oil temperature influenced AE levels. Whilst this would not directly enhance fault identification, it would provide important information on what influences AE activity within the gearbox. These new tests were carried out using 
the same test set-up, but in this instance the AE r.m.s. and energy data were monitored and recorded continuously while oil temperature in the gearbox was also measured at fifteen minute intervals.

Continuous AE energy and r.m.s values were calculated in real time by the Analog to Digital Converter (ADC) controlling software. This software employed a hardware accelerator to perform calculations in real time. The hardware accelerator takes each value from the $\mathrm{ADC}$ and squares it. These results are added into an accumulator for a programmable time interval set by the user, $100 \mathrm{~ms}$ in this instance. The accumulator is cleared at the start of the time interval, and the accumulator value will only be stored at the end of the time interval. The r.m.s is then calculated by taking the square root of the sum of the accumulated squared ADC readings. The energy value computed was equivalent to the area under the time waveform and is measured in Atto-Joules. The time interval for acquisition was also set at $100 \mathrm{~ms}$.

These additional tests were run at three load conditions until the AE r.m.s., AE energy and oil temperatures stabilised. The tests were terminated when the AE parameters and oil temperatures remain stable for one hour. Stabilisation at the oil temperatures was achieved when the temperature remained within $0.2^{0} \mathrm{C}$ for the duration of one hour.

Figures 29 and 30 illustrates that the gearbox system only reached a stabilised temperature after at least 5 hours of continuous running for both speed conditions. The starting point for all three test conditions investigated was dependent on the ambient temperature prior to testing. A smoothening technique was applied to the continuous $\mathrm{AE}$ 
data using moving average of 255 points. From figures 31 to 34, it was noted that the AE r.m.s. and energy levels varied with time as the gear box reached a stabilised temperature. This implied that depending on what time the AE data was collected for a given speed and load condition, the variation in AE activity r.m.s could be as much as $33 \%(55 \mathrm{Nm})$ and $60 \%(110 \mathrm{Nm})$ for $745 \mathrm{rpm}$, and, $125 \%(55 \mathrm{Nm})$ and $48 \%(110 \mathrm{Nm})$ at $1460 \mathrm{rpm}$. The variation for energy ranged from $140 \%(55 \mathrm{Nm})$ and $107 \%(110 \mathrm{Nm})$ for $745 \mathrm{rpm}$, and, $300 \%(55 \mathrm{Nm})$ and $113 \%(110 \mathrm{Nm})$ at $1460 \mathrm{rpm}$. These values were calculated based on the variation between the minimum and maximum $\mathrm{AE}$ values (energy, r.m.s) for each test condition. For these particular tests the point at which the data was captured is highlighted in figures 31 to 34 . Thus, the AE signal captured during seeded defect tests were 'snapshots' that are largely influenced by load and oil temperature. As 'snapshots' only provide information at an instance in time, the repeatability of the derived AE parameters will be subjected to considerable variation. The influence of load and oil temperature on AE activity is directly linked to the oil film thickness between the meshing gears. The oil film thickness will influence the rate of wear and asperity deformation, both of which generate the AE activity.

Furthermore, it is postulated the AE r.m.s values for $55 \mathrm{Nm}$ and $110 \mathrm{Nm}$ fluctuated as a function of increasing oil temperature (figures 31 to 34) because the gear teeth surfaces attempted to strike a balance between increasing lubricant temperature and decreasing surface roughness (these tests were started from 'cold conditions' and the gears were not run-in). These two factors have opposing effects on the AE levels; the former increases $\mathrm{AE}$ levels as oil film thickness reduces and asperity contact increases. The latter reduces the $\mathrm{AE}$ levels as the gear teeth surfaces smoothen. Clearly, the initial 
lubricant temperature and surface roughness of the meshing gear teeth surface will determine the starting level of $\mathrm{AE}$ but the running/operating $\mathrm{AE}$ levels during temperature changing periods will reflect the balance described above and will be a function of operating time and rotational speed.

The complications of the effect of oil temperature on AE activity have far reaching consequences, particularly as most of the published work to date have not take cognisance of this effect. The authors of this paper believe it is fundamentally flawed to compare AE activity from defect free and/or simulated defect conditions under varying loads without accounting for the influence of oil temperature. Whilst researchers $[6,9$, 10] have stated that $\mathrm{AE}$ indicators such as r.m.s. and energy increased with increasing load and speed, none have taken cognisance of the effect of temperature on AE activity. Clearly measuring the load and speed will cause a change in lubricant temperature. The authors believe that the lubricant temperature is an influential factor in the $\mathrm{AE}$ generation, in addition to the rotational speed and load. This implies that whilst other researchers have stipulated the effect of load/speed on AE activity, the time of data acquisition, in effect the temperature of the lubricant, will determine what values of r.m.s. are obtained. If as observed in this paper, the AE parameters continually change for several hours, the data presented by other researchers are subjected to environmental conditions. Even if attempts were undertaken to collect AE data at specified times, the effect of ambient temperature, which will influence the temperature at which the data is collected, could present inconsistencies or repeatability issues. Developing AE as a robust diagnosis tool without taking cognisance of the temperature influence will subject to error. 
Temperature variations do not have a direct influence in this particular study, where comparative AE signatures associated with each tooth have been analysed. This is because at the time of data acquisition all teeth will experience the same lubricant temperature. However, the influence of temperature on $\mathrm{AE}$ levels has not been previously assessed in the context of gearbox diagnosis with AE. The effect of oil temperature variation on generation of $\mathrm{AE}$ activity is currently under investigation and will be the subject of a future publication. It may be worth stating that the influence of oil temperature on AE activity for the higher rotational speed $(1460 \mathrm{rpm})$ showed relatively greater variations than that at $745 \mathrm{rpm}$.

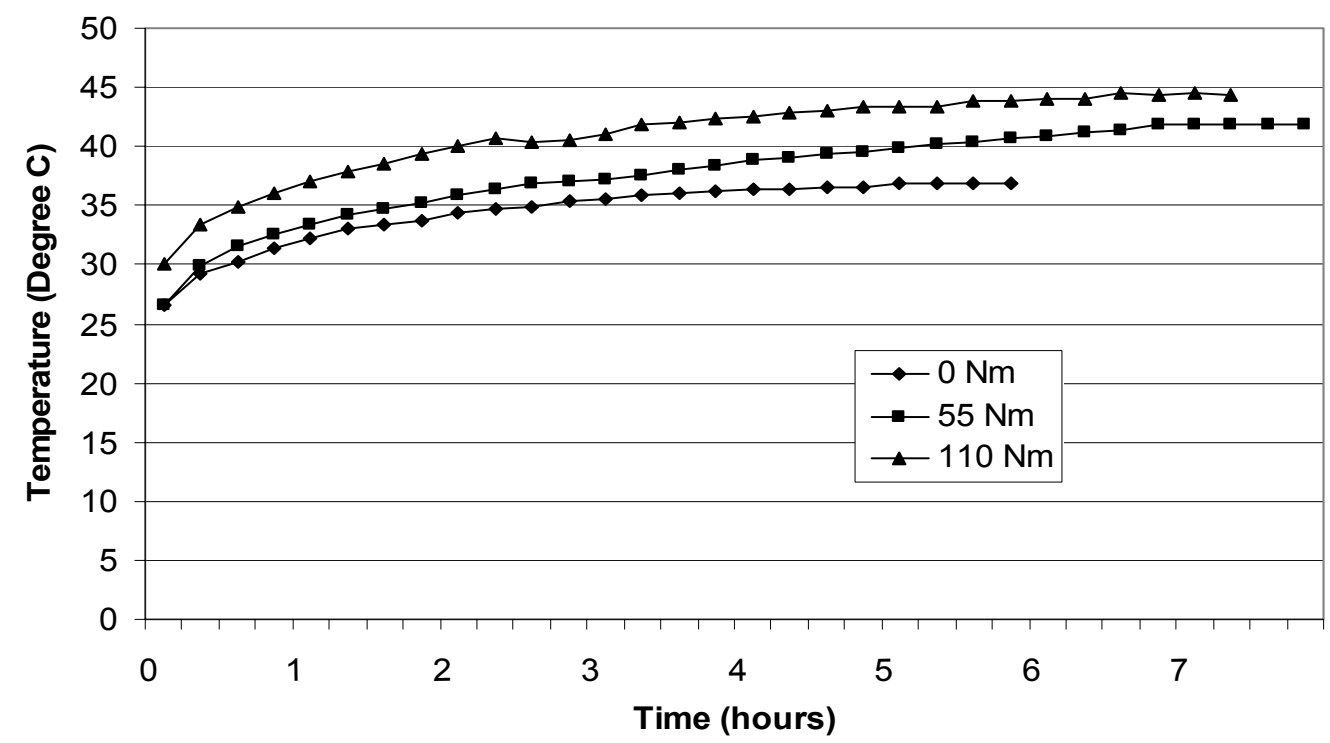

Figure 29 Oil temperatures monitoring with no-load, 55 Nm-load and 110 Nmload conditions at $745 \mathrm{rpm}$. 


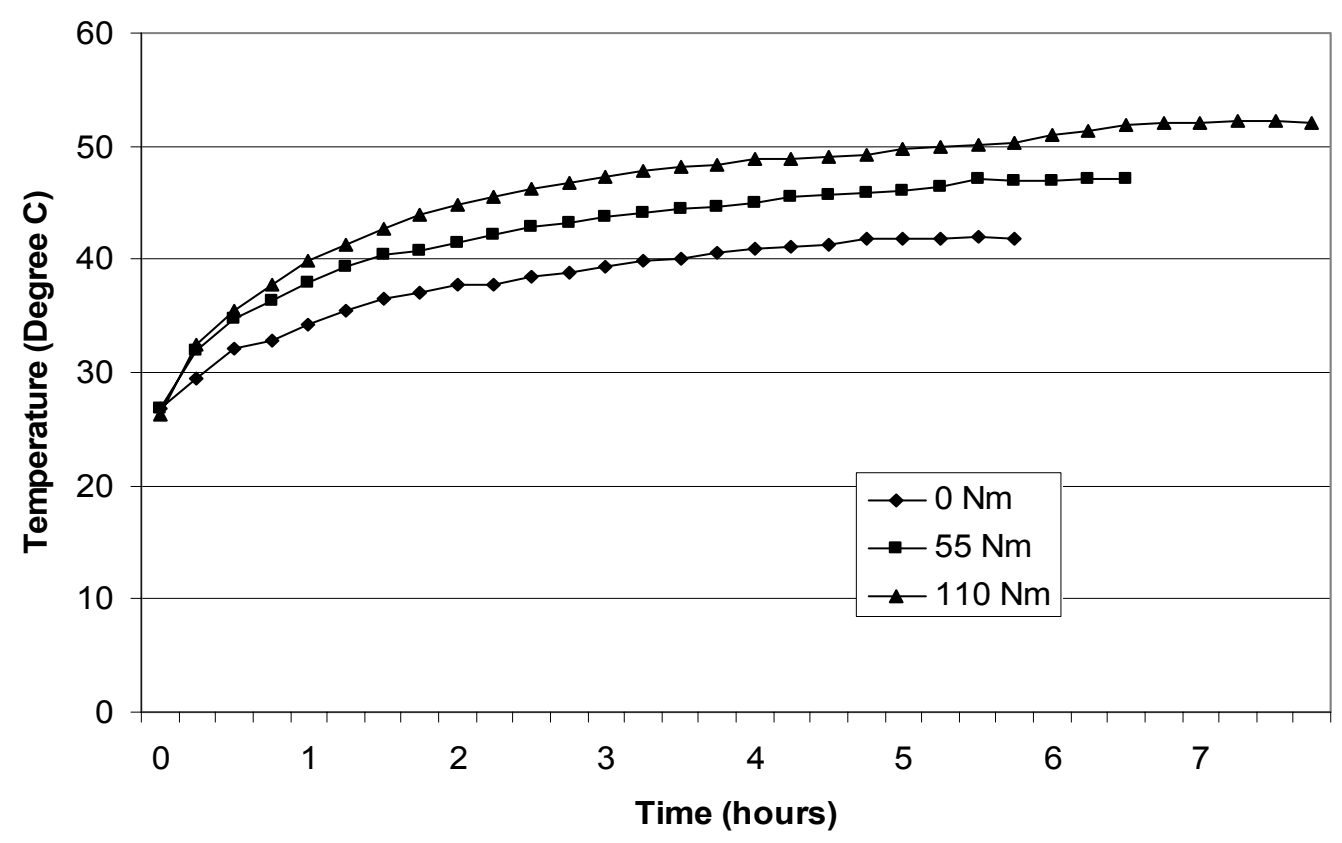

Figure 30 Oil temperatures monitoring with no-load, 55 Nm-load and 110 Nmload conditions at $1460 \mathrm{rpm}$.

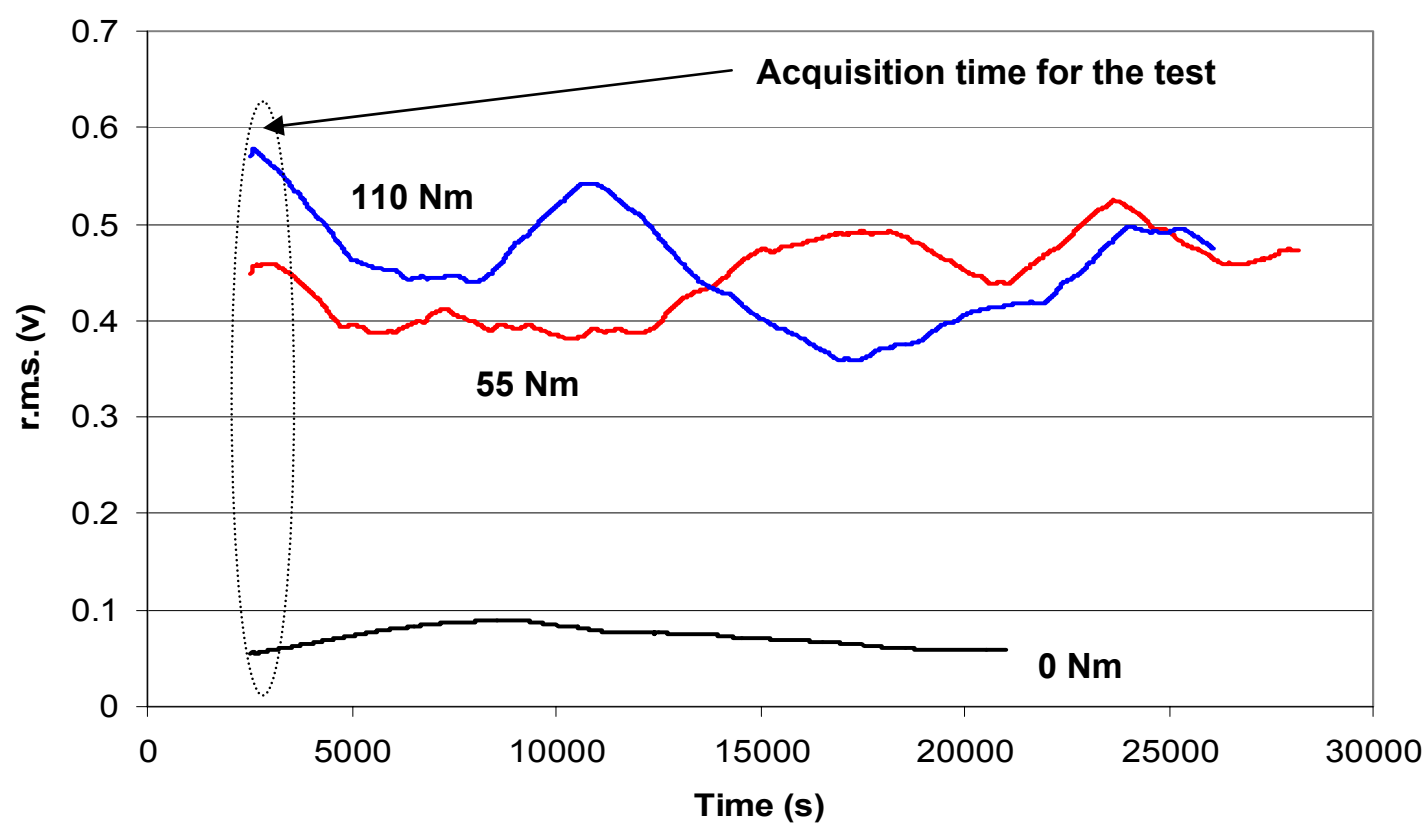

Figure 31 Continuous AE r.m.s values 745 rpm. 


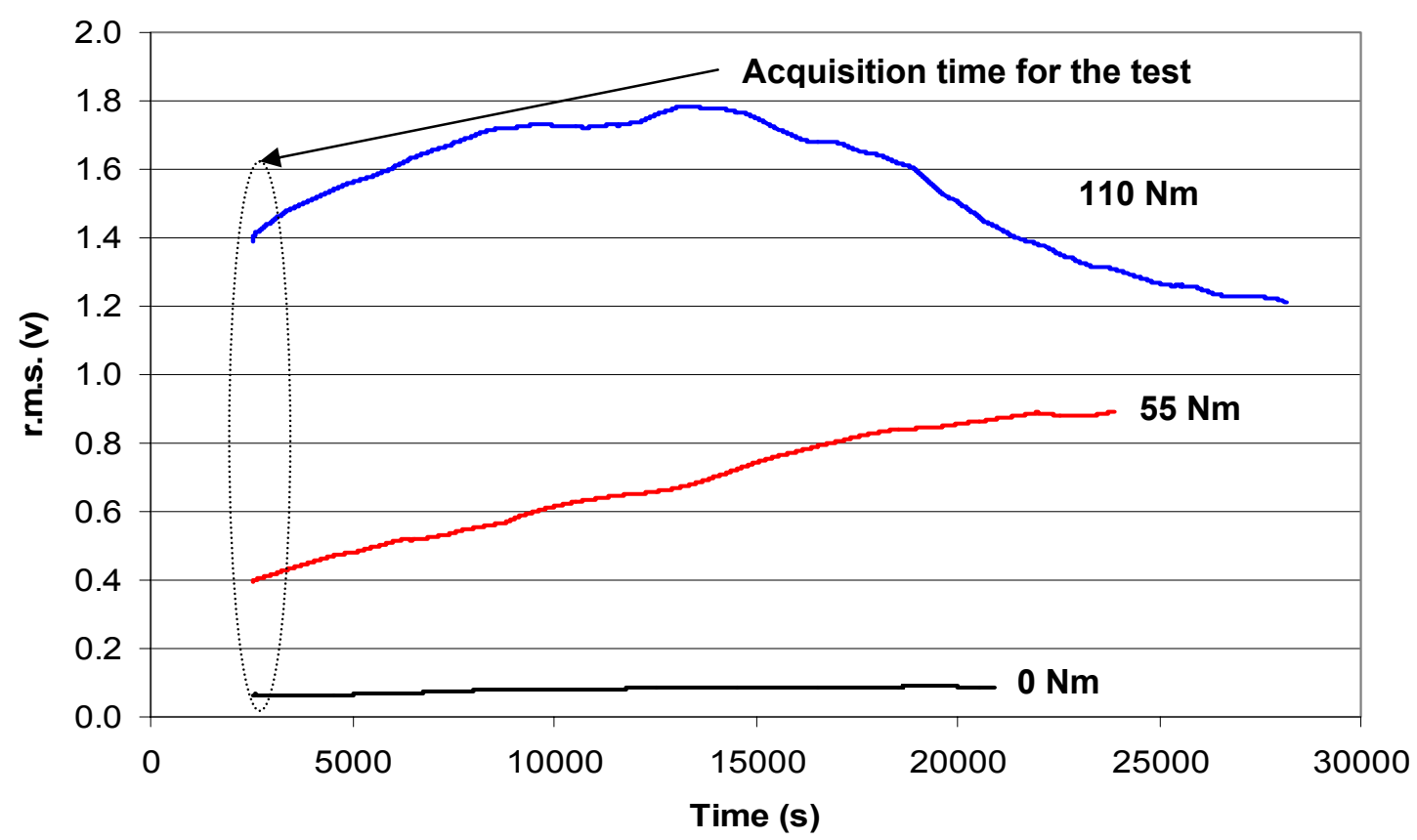

Figure 32 Continuous AE r.m.s values 1460 rpm.

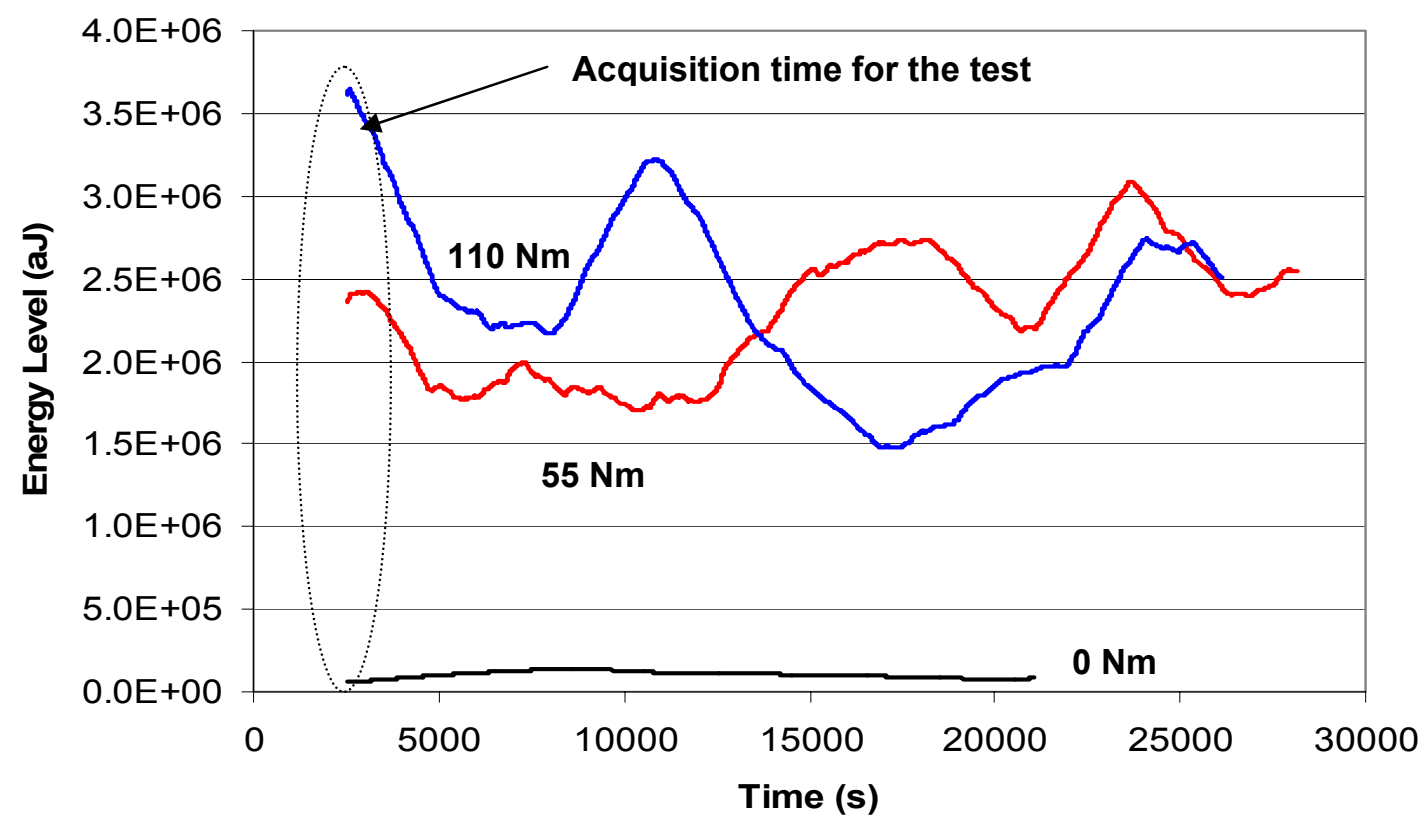

Figure 33 Continuous AE energy levels 745 rpm. 


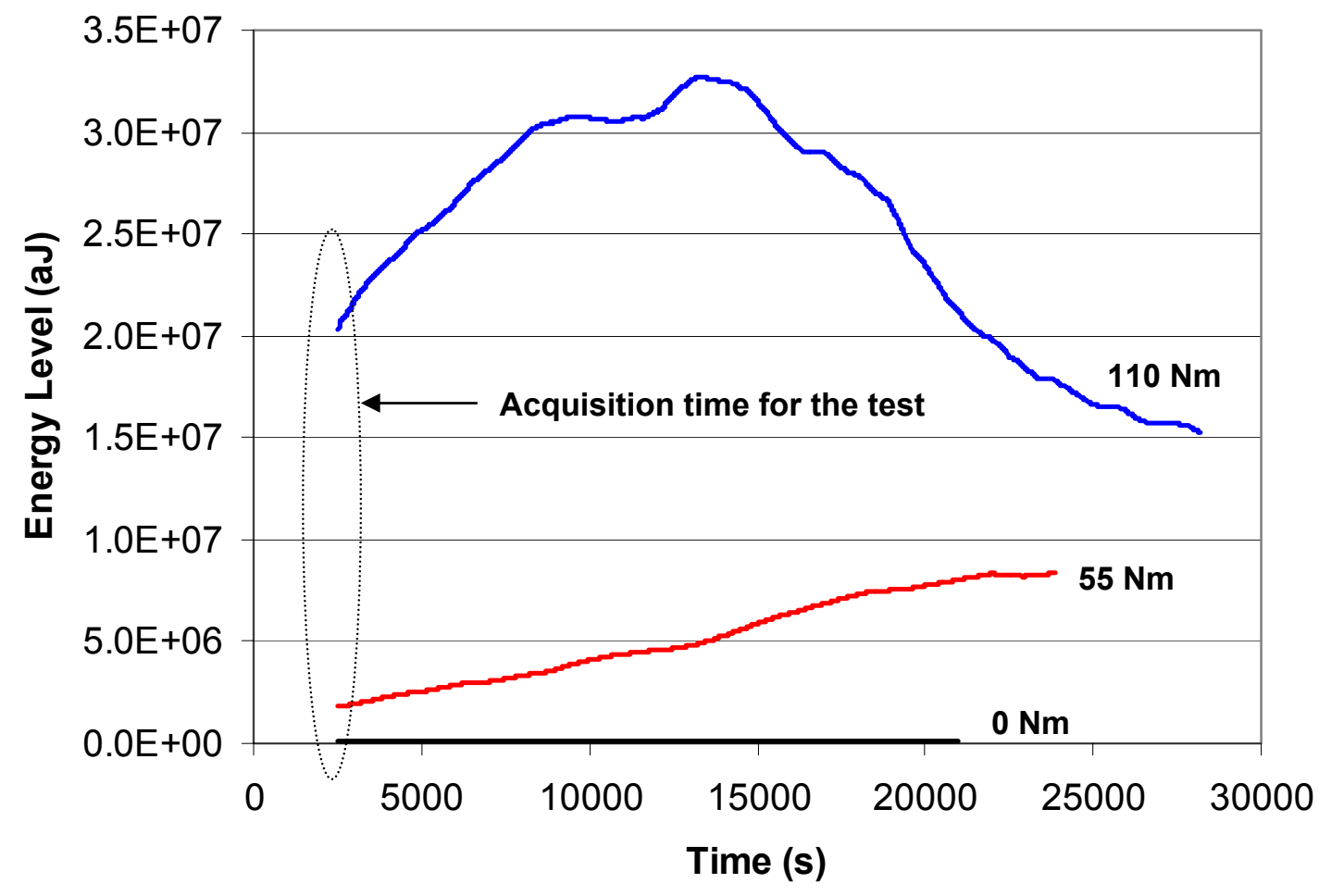

Figure 34 Continuous AE energy levels 1460 rpm.

Taking cognisance that AE activity is generated during the sliding of the gears, principally due to asperity contacts [13], the introduction of a seeded defect which removes surface material digresses from the basic source of $\mathrm{AE}$ generation. Therefore the authors argue that defect identification of seeded defects of this nature cannot be accomplished with the AE technique. This statement will hold true if the seeded defect involved the removal of material from the surface. However, other authors $[6,9,10]$ have claimed success and it is argued that the more likely reason for this is as follows: It is highly possible that in the process of material removal from the gear face 'mounds' or 'protrusions' will be formed at the boundaries of the seeded defect, see figure 35 . These are created due to the displacement of material from the region of material removal. The 
authors postulate that it is these 'protrusions' that was responsible for AE activity. However, this activity will only last until the 'protrusions' are flattened during the operation of the gear, see figure 36. In the later instance, AE will be generated by asperity contacts.

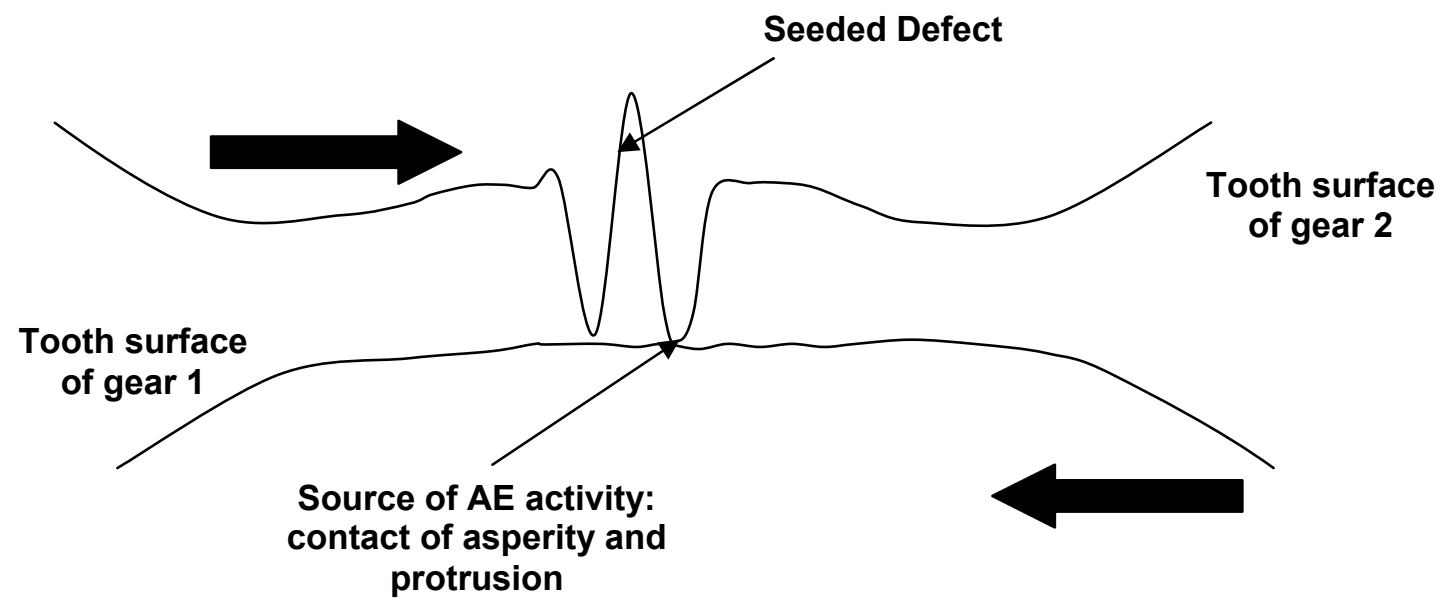

Figure 35 Mounds or Protrusions of the gear surfaces in contact during rotation.

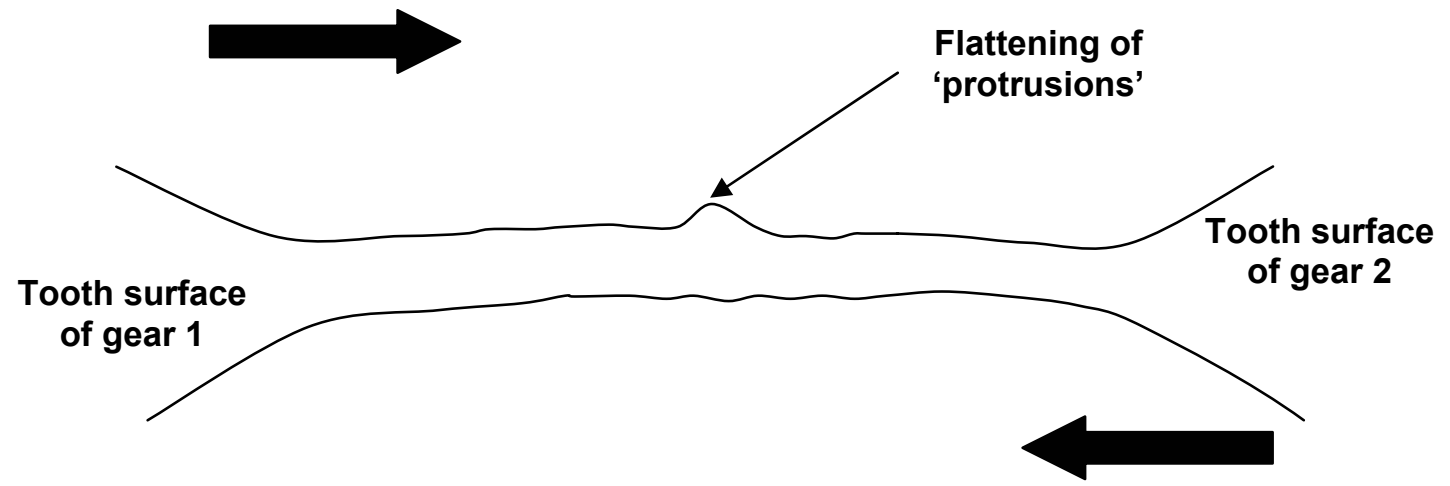

Figure $36 \quad$ Flattened protrusions of gear surfaces

The wear or pitting process of gears involves initiation of micro-cracks, crack growth and the removal of tiny particles from the gear surface which will emit AE. 
Furthermore, the removed wear particles or debris trapped between mating gear surfaces will create third-body abrasions. This condition will further enhance generation of AE signatures. For a better assessment on the detection capability of AE, it is recommended to perform the experiment in a condition which natural pitting or wear is allowed (i.e. gear fatigue test) rather than seeded defect test. AE parameters such as r.m.s. and energy can be used to monitor the gear fatigue process, though natural defects will possibly only generate $\mathrm{AE}$ transients for relatively short time periods superimposed on random operational noise. Due consideration must be given to this in developing a diagnostics tool to relate gear wear to AE activity. This diagnostic approach is currently under investigation.

\section{Conclusion}

This paper has demonstrated that artificially seeded gear defect detection with AE is fraught with difficulties. Experiments to identify seeded defect identification with AE r.m.s. and energy were not satisfactory. The influence of oil temperature on AE activity has been presented. This work is part of an ongoing program which aims to further investigate some of the drawbacks detailed.

\section{References}

1. Mba, D. and Bannister, R.H. (1999). Condition monitoring of low-speed rotating machinery using stress waves: Part1 and Part 2. Proc Inst Mech Engrs. 213(3), Part E, 153-185. 
2. Holroyd, T. and Randall, N. (1992). The Use of Acoustic Emission for Machine Condition Monitoring. British Journal of Non-Destructive Testing. 35(2), 75.

3. Mba D. (2001). The detection of shaft-seal rubbing in large-scale turbines using acoustic emission. 14th International Congress on Condition Monitoring and Diagnostic Engineering Management (COMADEM'2001). Manchester, UK, 4-6 September 2001. 21-28, ISBN 0080440363.

4. Mba, D. (2002). Applicability of acoustic emissions to monitoring the mechanical integrity of bolted structures in low speed rotating machinery: case study. NDT and E International. 35(5), 293-300.

5. Mba, D., Cooke, A., Roby, D. and Hewitt, G. (2003). Opportunities offered by acoustic emission for shaft-seal rubbing in power generation turbines; a case study. International Conference on Condition Monitoring. Oxford, sponsored by the British Institute of NDT UK, 2-4 July 2003. 280-286, ISBN 1901892174.

6. Siores, E. and Negro, A.A. (1997). Condition Monitoring of a Gear Box Using Acoustic Emission Testing, Material Evaluation, (183-187).

7. Sentoku, H. (1998). AE in Tooth Surface Failure Process of Spur Gears, Journal of Acoustic Emission, 16(1-4), S19-S24.

8. Singh, A., Houser, D. R., and Vijayakar, S. (1999). Detecting Gear Tooth Breakage Using Acoustic Emission: A Feasibility and Sensor Placement Study, Journal of Mechanical Design, 121, 587-593.

9. Singh, A., Houser, D. R., and Vijayakar, S. (1996). Early Detection of Gear Pitting. Power Transmission and Gearing Conference, ASME. DE-Vol. 88, 673678. 
10. Tandon, N. and Mata, S. (1999). Detection of Defects in Gears by Acoustic Emission Measurements. Journal of Acoustic Emission. 17(1-2), 23-27.

11. Al-Balushi, K. R., and Samanta, B. (2002). Gear Faults Diagnosis Using EnergyBased Features of Acoustic Emission. Proc. Instn Mech Engrs, Journal of Systems and Control Engineering. 216, Part I, 249-263.

12. Toutountzakis, T. and Mba, D. (2003). Observation of Acoustic Emission Activity During Gear Defect Diagnosis. NDT and E International. 36(7), 471-477.

13. Boness, R.J. and McBride, S.L., Adhesive and abrasive wear studies using acoustic emission techniques. Wear. Vol. 149, 41-53, 1991. 